\title{
El CONTROL DE LA RESOLUCIÓN MOTIVADA QUE AUTORIZA UNA INTERCEPTACIÓN TELEFÓNICA EN CHILE Y DURACIÓN DE LA MEDIDA*
}

[The Control of the Resolution Setting Out the Grounds on Which it is Based That Authorises the Interception of Telephonic Communications in Chile and the Duration of the Measure]

\section{Agustina Alvarado Urízar ${ }^{* *}$}

\begin{abstract}
ReSUMEN
El trabajo examina el procedimiento chileno de autorización judicial de interceptaciones telefónicas desde la perspectiva de los sistemas de control referidos a la motivación de la resolución judicial autorizante de la intervención y su duración; y ofrece una breve reseña histórica de la figura. Se pone de manifiesto la indisoluble relación entre una adecuada motivación y el conocimiento efectivo que de la misma tenga el titular del derecho menoscabado.
\end{abstract}

\section{Palabras Clave}

Interceptación telefónica - intervención de comunicaciones - autorización judicial; motivación - control.

\section{Abstract}

From the standpoint of the control systems referring to the grounds on which the legal resolution authorises the interception and duration of telephone communications, this work examines the Chilean procedure of legal authorisation of telephone communications interception; and offers a brief historical background of this concept. The indissoluble link between the due grounds and the actual information the holder of the undermined right has about this is presented.

\section{KeYwords}

Telephonic interception - interception of communications - legal authorisation; grounds - control.

RECIBIDo el 31 de octubre y ACEPTADO el 22 de diciembre de 2014

* Este trabajo ha sido redactado en el marco del proyecto de investigación FONDECYT Regular N 1130422, "Formulación de una teoría general de las medidas coercitivas contra el imputado en el proceso penal con base en el derecho procesal penal chileno: estudio dogmático y crítico", bajo la dirección del profesor Dr. Guillermo Oliver Calderón.

** Estudiante del Programa de Doctorado de la Università degli Studi di Milano. Correo electrónico: agustina.alvarado@unimi.it 


\section{INTRODUCCIÓN}

Ya en 1989 López de Quiroga se detenía a analizar las restricciones que deberían esbozarse en la aplicación de las operaciones de interceptación telefónica en varios aspectos fundamentales, tales como: $i$ ) el delito; $i i$ ) el tiempo; $i i i)$ el espacio; $i v$ ) la persona ejecutante; $v$ ) el procedimiento; y $v i$ ) el medio de ejecución ${ }^{1}$. En el presente trabajo nos centraremos en el estudio de las restricciones relativas al tiempo de duración de las operaciones de interceptaciones y aquellas que se refieren al procedimiento establecido para tramitar su procedencia, donde se ubica la cuestión de la fundamentación del decreto que autoriza la medida y la notificación al afectado por la misma.

Estos extremos serán analizados desde la óptica del control. En efecto, atendido que "la garantía representada por la motivación opera bajo un doble aspecto: al interno, en cuanto induce al juez a una mayor ponderación antes de emitir la resolución restrictiva; y al externo, en cuanto permite al interesado solicitar un control jurisdiccional -si bien no inmediato- sobre la resolución misma, en caso que resulte carente de "motivos"' 2 , la investigación apuntará precisamente a esta triangulación. Además, se esbozará la incidencia que un precario sistema de control produce en relación con el derecho al plazo razonable y con el derecho de defensa ${ }^{3}$, desde un enfoque que urge poner en discusión. De hecho, atendida la extensión de este trabajo y la entidad de las cuestiones puestas en debate, su pretensión apunta más a promover inquietudes que a ofrecer tajantes soluciones.

${ }^{1}$ López DE Quiroga, Jacobo, Las escuchas telefónicas y la prueba ilegalmente obtenida (Madrid, Akal, 1989), p. 150 ss.

${ }^{2}$ GREvi, Vittorio, Appunti in tema di intercettazioni telefoniche operate dalla polizia giudiziaria, en Rivista italiana di diritto e procedura penale, 10 (1967) 2, p. 729 . La traducción es nuestra. Tal idea es reiterada en GrEvi, Vittorio, Intercettazioni telefoniche e principi costituzionali, en Rivista Italiana di Diritto e Procedura Penale (1971), pp. 1064-1082.

${ }^{3}$ Si bien el derecho de defensa ha sido desde antiguo objeto de análisis en relación con la regulación de las interceptaciones telefónicas, entendemos que no se ha efectuado desde la perspectiva abordada en el presente trabajo. Sobre la perspectiva tradicional de tratamiento puede revisarse Grevi, Vittorio, Intercettazioni telefoniche, cit. (n. 2), pp. 1064-1082, donde se comenta la sentencia de 13 de octubre de 1971 del Tribunal de Roma en orden a la eventual ilegitimidad de las interceptaciones telefónicas respecto de la garantía del silencio del derecho de defensa del imputado, p. 1968. "Più precisamente, se si ritiene che la garanzia del diritto al silenzio -quale espressione 'passiva' del diritto di difesa costituzionalmente tutelato- riguarda le sole ipotesi in cui l'inquisito si trovi di fronte all' autorità (di polizia o giudiziaria), in posizione di più o meno mancata soggezione psicologica, se ne deve desumere che tale garanzia non resulta compromessa dall' istituto delle intercettazioni telefoniche". 


\section{EVOLUCiÓN NORMATIVA DESDE LA PERSPECTIVA DEL CONTROL \\ INTERNO EN MATERIA DE INTERCEPTACIÓN TELEFÓNICA: MOTIVACIÓN DEL DECRETO AUTORIZANTE DE LA MEDIDA Y SU DURACIÓN}

\section{Marco normativo chileno del sistema inquisitivo,}

El Código de Procedimiento Penal de 1906 no conocía operaciones de interceptación telefónica, por lo que sus orígenes en Chile provienen de leyes especiales ${ }^{4}$. En este sentido, en primer término se encuentra la Ley $\mathrm{N}^{\circ}$ 18.314 que determina conductas terroristas, y fija su penalidad (D. O. de 17 de mayo de 1984) $)^{5}$. Este cuerpo normativo contenía la medida intrusiva en su artículo 14, dl cual permitía solicitar la interceptación, apertura o el registro de comunicaciones y documentos privados o la observación, por cualquier medio, de personas sospechosas de la comisión o preparación de delitos terroristas. Señalaba expresamente que dicha resolución debía ser fundada, dictarse sin conocimiento del afectado, y que la misma no era susceptible de recurso alguno. En cuanto a su duración, tales medidas no podían decretarse por un plazo superior a 30 días, prorrogables hasta por igual período 6 .

No obstante el carácter excepcional de la materia en que se prevé el instituto y, sin perjuicio del periodo histórico en que tuvo lugar su dictación

${ }^{4}$ Sobre la posibilidad de estimar existente la medida de interceptación telefónica en la regulación de los artículos 176 y 177 CdePP, véase el análisis de Gálvez Blanco, Ricardo, Intervención de teléfonos en la legislación chilena, en Revista Chilena de Derecho, 19 (1992) 3, pp. 481-487. Si bien arriba a una conclusión negativa, el profesor Gálvez esboza los requisitos, límites y controles con que la interceptación telefónica debiese consagrarse en perspectiva de reforma.

${ }^{5}$ Historia de la Ley $N^{\circ}$ 18.314: Determina conductas terroristas y fija su penalidad (D.O. de 17 de mayo de 1984, p. 4, disponible en: http://www.leychile.cl/Consulta/ portada_hl?tipo_norma $=X X 1 \&$ nro_ley $=18314 \&$ anio $=2014$. En su tramitación, tanto el mensaje del Ejecutivo como los informes de Secretaría de la Junta de Gobierno, expresaban la necesidad de contar con herramientas legales que permitiesen procesos ágiles y sanciones adecuadas para este tipo de criminalidad. Se indicaba que las importantes consecuencias derivadas de la actividad terrorista, hacían indispensable acentuar las medidas preventivas a su respecto. El mensaje del Ejecutivo señalaba tener a la vista el surgimiento de distintas leyes en otros países tanto americanos como europeos, "destacándose la reciente ley peruana, la legislación española, italiana y alemana", sin que en todo caso exista referencia expresa a una contribución específica de estos ordenamientos.

${ }^{6} \mathrm{Su}$ inciso $2^{\circ}$ agregaba que en casos de urgencia, la medida podía ser ordenada por el ministro del Interior, comunicándolo al tribunal respectivo, por escrito y dentro de las 24 horas siguientes. Luego, el tribunal, mediante resolución fundada, podía revocar o confirmar tal medida en un plazo máximo de 72 horas, desde que fuera ordenada la interceptación, apertura o registro. 
(plena fase de dictadura), inmediatamente sobresalen dos aspectos, a saber: i) la exigencia de fundamentación de la resolución judicial autorizante; y ii) la expresa delimitación de su duración y posibilidad de prórroga. Mientras la exigencia de fundamentación de la resolución se vuelve inocua debido a la ausencia de todo parámetro que determine su contenido y a la imposibilidad de revisión de la decisión (conexión con el control externo); el segundo aspecto anotado, esto es, el breve periodo de observación consagrado en la norma, es un intervalo que no se vuelve a repetir en la historia de la legislación chilena. En efecto, el tenor literal de la redacción sobre la posibilidad de prórroga, expresa claramente su procedencia en una única oportunidad, siendo posible calcular un periodo de observación máximo de 60 días.

En materia de tráfico de drogas y sustancias estupefacientes, la Ley $\mathrm{N}^{\circ}$ 19.366 (D.O. 30 de enero de 1995), constituye el primer cuerpo legal en contemplar operaciones de interceptación telefónica con respecto a su materia ${ }^{7}$. El artículo 31 disponía la posibilidad del juez del crimen, a solicitud fundada del organismo policial que investigase alguno de los delitos contemplados en esta ley, de autorizar la intervención, apertura o registro de comunicaciones o documentos privados, o la observación, por cualquier medio, de aquellas personas respecto de las cuales existiesen fund a d a $\mathrm{s}$ sospechas de que interviniesen en la preparación o comisión de estos delitos. Se indicaba expresamente que la resolución debía ser fundada y dictada sin conocimiento del afectado. Temporalmente, las medidas no podían decretarse por un plazo superior a 20 días, prorrogable por igual período. Por último, contenía expresamente la sanción de inhabilitación temporal para el ejercicio de cargos y oficios públicos por el abuso de poder en el ejercicio de estas atribuciones. Si bien la disposición no fue objeto de especiales reparos durante su tramitación ${ }^{8}$, cabe subrayar el periodo de observación máximo planteado, toda vez que su tenor literal forzosamente implica la procedencia

${ }^{7} \mathrm{La}$ anterior ley sobre la materia, esto es, la Ley $\mathrm{N}^{\circ} 18.403$, no contenía referencia alguna a medios de investigación tales como la interceptación de comunicaciones.

${ }^{8}$ La norma fue aprobada en los mismos términos en que fue propuesta por el ejecutivo, Historia de la Ley $\mathrm{N}^{\circ}$ 19.366: Sanciona el tráfico ilícito de drogas y sustancias estupefacientes, dicta y modifica diversas disposiciones legales y deroga Ley $N^{\circ} 18.403$ (D. O. de 30 de enero de 1995), p. 20, disponible en: http://www.leychile.cl/Consulta/portada_hl?tipo_norma $=X X 1 \&$ nro_ley $=193668$ anio $=1995$. Solo en el Segundo Trámite Constitucional del Senado es posible encontrar una opinión discrepante proveniente del Senador Otero, quien estimó que la redacción de la norma no era adecuada, ya que, en los términos en que estaba concebida, afectaría garantías constitucionales relacionadas con el derecho a la privacidad de las personas, consagrado en el artículo $19 \mathrm{~N}^{\circ} 4$ C.Pol. A vía de ejemplar, señaló que, al interceptarse las llamadas telefónicas, podían verse afectados ciudadanos que no tuvieran ninguna relación con quien trafica, e incluso desconocieran que realizaba esta actividad ilícita. En este trámite, la Comisión 
de una única prórroga y por ende, de un plazo máximo de 40 días. En materia de fundamentación de la resolución judicial, el precepto sigue careciendo de una adecuada precisión sobre su contenido. Sin embargo, a diferencia del caso anterior, la historia de la ley da luces sobre el estándar que debe alcanzar dicho contenido. En efecto, en la discusión particular incluida en el informe del segundo trámite constitucional del Senado se expresa: "el señor Ministro de Justicia subrayó que la disposición exige que existan fundadas sospechas, es decir, los mismos requisitos que se necesitan, según lo dispone el artículo 252 del CPP, para detener a una persona. La diferencia es que, en esta situación, no se materializa la detención con el propósito de seguir la red de tráfico".

Tardíamente, con ocasión de la reforma en materia de persecución y represión de la pornografía infantil, la Ley $\mathrm{N}^{\circ} 19.927$ (D.O. de 14 de enero de 2004) introdujo las medidas de interceptación telefónica ${ }^{10}$. Así, el nuevo artículo 113 ter. de este cuerpo normativo establece la procedencia de la interceptación telefónica cuando existieren "sospechas fundadas" de que una persona o una organización delictiva hubiere cometido o preparado la comisión de alguno de los delitos previstos en los artículos 366 quinquies, 367,367 bis, 367 ter, 374 bis inciso $1^{\circ}$ y 374 ter CPen., y la investigación lo hiciere imprescindible. En lo pertinente, indica que la orden que dispusiere la interceptación o grabación deberá indicar el nombre o los datos que permitan la adecuada identificación del afectado por la medida y señalar la forma en que se aplicará y su duración, la que no podrá exceder de 60 días. Además, el juez podrá prorrogar este plazo por períodos de hasta igual duración, para lo cual deberá examinar cada vez la concurrencia de los requisitos previstos en los incisos precedentes. En todo caso, la orden judicial no podrá extenderse más allá de 1 año desde que se decretó. Si las sospechas valoradas para ordenar las medidas se disiparen o hubiere transcurrido el plazo de duración fijado para las mismas, ellas deberán ser interrumpidas inmediatamente. Es decir, no obstante contemplarse un número de prórrogas indefinidas, el plazo máximo de 1 año desde la dictación del primer decreto autorizante es un límite novedoso que no se contiene en las otras materias donde se prevé la interceptación de comunicaciones.

En cuanto al aspecto temporal, la Corte Suprema señaló que atendido que

aprobó el artículo por mayoría de votos. Los emitieron afirmativamente los senadores Fernández, Letelier y Pacheco, y se abstuvo el senador Otero, p. 422.

${ }^{9}$ Historia de la Ley $N^{\circ} 19.366$, cit. (n. 8), p. 422.

${ }^{10}$ Para un análisis de las modificaciones introducidas por la Ley $\mathrm{N}^{\circ} 19.927$ Código Priocesal Penal (en particular al artículo 222), véase: DuQue González, Catalina, El agente encubierto y la interceptación o grabación de telecomunicaciones en las investigaciones de delitos sexuales, en Revista Jurídica del Ministerio Público, 46 (marzo de 2011), pp. 143-153. 
se trataba de una severa injerencia en el ámbito de actividad de los afectados, creía prudente establecer que ellas podrían decretarse por un tiempo determinado, cuya extensión se fijara en la misma ley, pudiendo prorrogárselas por una sola vez. Luego, en una segunda intervención, pronunciándose sobre el establecimiento del plazo máximo de 1 año, por los mismos motivos, la CS señaló parecerle excesivo e insinuó su sustitución por uno de 6 meses ${ }^{11}$, mostrándose consciente de la afectación de derechos que una desmedida extensión temporal puede implicar para el sujeto intervenido.

\section{Marco normativo chileno del sistema acusatorio}

La entrada en vigencia del nuevo Código Procesal Penal chileno contiene como novedad la regulación de las interceptación telefónica con carácter general -respecto de hechos que merecieren pena de crimen-, en los artículos 222 ss. Se trata de una medida intrusiva que afecta el derecho constitucional de la intimidad, contenido en el artículo $19 \mathrm{~N}^{\circ} 4$ y 5 CPol., esto es, respectivamente, el respeto y protección de la vida privada y la inviolabilidad de toda forma de comunicación privada ${ }^{12}$, cuya afectación, está sometido al principio de reserva de ley y su concreción, por ende, regulada en el Código Procesal Penal y en las leyes especiales respectivas.

En el primer trámite constitucional del proyecto de reforma del Código Procesal Penal, la Cámara de Diputados consideró que en esta materia se habían cometido grandes errores y abusos, por lo que no le parecía razonable conceder a los jueces esta facultad. Se calificó de paradojal, que este proyecto, proclamado como "garantístico", rompiera algo tan íntimo como el derecho a la personalidad y a la vida privada, por lo que en definitiva, todos los artí-

${ }^{11}$ Historia de la Ley $N^{\circ}$ 19.927: Modifica el Código penal, el Código de Procedimiento Penal y el Código Procesal Penal en materia de delitos de pornografía infantil, DO. 14.1.2004, p. 85 y 146, respectivamente, disponible en: http://www.leychile.cl/Consulta/portada_hl?tipo_norma $=X X 1 \&$ nro_ley $=19.927 \&$ anio $=2014$.

${ }^{12}$ Para un examen exhaustivo del derecho fundamental vulnerado véase: PASTÉN PÉREZ, Dagoberto, Régimen jurídico de las medidas de interceptación de las comunicaciones telefónicas previstas en el Código Procesal Penal (Tesis, Universidad de Valparaíso, Chile, Escuela de Derecho), 138 p. 
culos referidos a las interceptación telefónica fueron rechazados ${ }^{13-14}$. Luego, en la discusión particular contenida en el segundo informe de la Comisión de Constitución del Senado, se estimó necesario reponer tales normas, por considerar que determinados delitos, por su complejidad o gravedad, podían ver seriamente dificultada su investigación al no contar con la posibilidad de adoptar esta medida. Además, se indicó que la lógica de la interceptación telefónica no difería en lo sustancial de la retención e incautación de correspondencia regulada en el artículo 290 y que, por lo demás, el artículo 19 No5 CPol., que consagra la inviolabilidad de las comunicaciones privadas, permitía que la ley determinara la forma en que éstas pueden interceptarse, abrirse o registrarse. No obstante, estimó excesivo permitir la interceptación telefónica en todo delito que mereciere pena aflictiva, según disponía el "Mensaje". Por ello elevó la exigencia a que el delito investigado mereciere pena de crimen, asegurando su procedencia sólo respecto de delitos de mayor

${ }^{13}$ Historia de la Ley $N^{\circ}$ 19.696: Establece Código Procesal Penal (D.O. de 12 de octubre de 2000), p. 643 s., disponible en: http://www.leychile.cl/Consulta/portada hl?tipo_norma $=X X 1 \&$ nro_ley=19.696\&anio=2014. Se indicó que el juez de control no era ninguna garantía frente a esta situación, por lo que la interceptación telefónica debía mantenerse como una medida muy excepcional, en leyes especiales, para la investigación de ciertos delitos específicos, como los de terrorismo, narcotráfico o en contra de la seguridad del Estado. En contra, se argumentó que la reforma preveía un investigador, encargado de descubrir la verdad, y a un juez completamente imparcial y desinteresado de esa función, siendo ella la principal garantía del sistema, sin perjuicio de que se establecieran otras, si se estimaba necesario. Se agregó que todas las medidas cautelares y todas las medidas de investigación afectaban derechos individuales, e invadían distintos ámbitos de privacidad. Sin embargo, el argumento anterior fue rebatido, por estimarse que la interceptación de comunicaciones era una invasión completa del campo de la libertad e intimidad de la persona.

${ }^{14}$ En la discusión particular en Sala de la Cámara de Diputados es posible encontrar constancia expresa de esta posición en las intervenciones de los diputados Elgueta y Aldo Cornejo. El primero hizo presente la precaria regulación actual del cumplimiento de la garantía constitucional de la inviolabilidad de las comunicaciones. Aún más, indicó que a su juicio, las leyes de conductas antiterroristas y sobre narcotráfico, eran preceptos inconstitucionales, porque permitían captar o interrumpir las comunicaciones en los casos y formas señaladas por la ley, sin que en ellas se señalara la forma en que debía efectuarse la intervención telefónica (en cuanto a qué funcionarios deben hacerlas, en qué aparatos, si esos funcionarios deben guardar sigilo o no, si quienes los individualizan serán testigos más adelante, etc.). Por su parte, al diputado Cornejo le pareció oportuno dejar constancia de su adhesión a la posición mayoritaria de oponerse a la idea de establecer la interceptación telefónica o de las comunicaciones privadas como regla general para cualquier delito, por considerarlo una exageración y, se manifestó conforme con que dicho procedimiento estuviera más bien contenido en leyes especiales, sin perjuicio de estudiar su perfección. Historia de la Ley $\mathrm{N}^{\circ} 19.696$, cit. (n. 3), p. 659 s. y 673 , respectivamente. 
gravedad $^{15}$. Con lo señalado quedó prácticamente determinada la actual redacción de la regulación de la interceptación telefónica en los términos previstos en los artículos 222 ss. CPP., que repercutiría en la regulación del instituto contenida en leyes especiales.

El artículo 222 CPP. establece que en casos en que existieren fund a d as sospechas, basadas en "hechos determinados", de que una persona hubiere cometido o participado en la preparación o comisión, o que ella preparare actualmente la comisión o participación en un hecho punible que mereciere pena de crimen, y la investigación lo hiciere imprescindible, el juez de garantía, a petición del ministerio público, podrá ordenar la interceptación y grabación de sus comunicaciones telefónicas o de otras formas de telecomunicación. Según su inciso $2^{\circ}$, tal orden sólo podrá afectar al imputado o a personas respecto de las cuales existieren sospechas fundadas, basadas en hechos determinados, de que ellas sirven de intermediarias de dichas comunicaciones y, asimismo, de aquellas que facilitaren sus medios de comunicación al imputado o sus intermediarios ${ }^{16}$. Con todo, las comunicaciones entre el imputado y su abogado no pueden ser interceptadas, a menos que el juez de garantía lo ordene, por estimar fundadamente, sobre la base de antecedentes de los que dejará constancia en la respectiva resolución, que el abogado pudiere tener responsabilidad penal en los hechos investigados.

El inciso $4^{\circ}$, señala que la orden que dispusiere la interceptación y grabación deberá indicar circunstanciadamente el nombre y dirección del afectado por la medida y señalar la forma de la interceptación y la duración de la misma, la que no podrá exceder de 60 días. Dicho plazo es susceptible de prórrogas por períodos de hasta igual duración, debiéndose examinar cada vez la concurrencia de los requisitos previstos en los incisos precedentes. Por último, el inciso final prescribe que si las sospechas tenidas en consideración para ordenar la medida se disiparen o hubiere transcurrido el plazo de duración fijado para la misma, ella deberá ser interrumpida inmediatamente. Esta norma deriva del carácter instrumental de la medida y de la regla rebus

${ }^{15}$ Historia de la Ley $N^{\circ} 19.696$, cit. (n. 3), pp. 1408 s.

${ }^{16}$ Nos encontramos frente a una flexibilización infundada de la norma. La primera parte de la disposición se refiere a la posibilidad de interceptar las comunicaciones de quien hubiese cometido o participado en la comisión o preparación. La expresión "participación”, entendida en su sentido penal, ya abarca a quienes sirven de intermediarios de dichas comunicaciones y a quienes facilitan sus medios de comunicación al imputado o sus intermediarios. Se trataría de la interceptación de comunicaciones de quienes ostenten la calidad de cómplices. Sin embargo, al diferenciar ambas situaciones, la norma permitiría erróneamente sostener que los antecedentes para solicitar la interceptación en uno y otro caso son distintos, de menor intensidad en el segundo, cuestión con la que no concordamos. En la misma línea se encuentra la opinión de LópEZ DE QUIROGA, Jacobo, cit. (n. 1), p. 188. 
sic stantibus, conforme a la cual sólo debe mantenérsela mientras subsista el fundamento que la hizo procedente"17.

En el contexto de la reforma procesal penal, el actual artículo 14 de la Ley $\mathrm{N}^{\circ}$ 18.314: Sobre conductas terroristas, ha variado su redacción, ajustándose a la introducción del nuevo proceso. De este modo prescribe que: "En los casos del artículo $1^{\circ}$ de esta ley, durante la audiencia de formalización de la investigación o una vez formalizada ésta, si procediere la prisión preventiva del imputado, el ministerio público podrá pedir al juez de garantía que decrete, además, por resolución fundada, todas o algunas de las siguientes medidas:/ [...] 3. Interceptar, abrir o registrar sus comunicaciones telefónicas e informáticas y su correspondencia epistolar y telegráfica". El inciso $2^{\circ}$ agrega: "las medidas indicadas precedentemente no podrán afectar la comunicación del imputado con sus abogados y la resolución que las imponga sólo será apelable en el efecto devolutivo. Sin perjuicio de lo anterior, en cualquier momento el ministerio público podrá solicitar autorización judicial para la realización de diligencias de investigación que la requieran, en los términos del artículo $236 \mathrm{del}$ Código Procesal Penal".

En materia de tráfico de drogas y sustancias estupefacientes, bajo la vigencia del nuevo Código Procesal Penal, se emitió la Ley $\mathrm{N}^{\circ} 20.000$ : Sustituye la anterior Ley $N^{\circ} 19.366$ (D. O. de 6 de febrero de 2005), cuyo artículo 24 permitió la aplicación de medidas de retención e incautación de correspondencia, obtención de copias de comunicaciones o transmisiones, interceptación de comunicaciones telefónicas y uso de otros medios técnicos de investigación, respecto de todos los delitos previstos en dicha ley y cualquiera sea la pena que merecieren, de conformidad a las disposiciones pertinentes del Código Procesal Penal. Su inciso $2^{\circ}$, señala que, sin perjuicio de lo anterior, no regirá lo dispuesto en el inciso $4^{\circ}$ del artículo $222 \mathrm{CPP}$. , en cuanto a indicar circunstanciadamente el nombre y dirección del afectado por la medida, siendo suficiente consignar las circunstancias que lo individualizaren o determinaren. Esta excepción, se contiene en el primer informe de la Comisión der Constitución del Senado, en segundo trámite constitucional, y fue incorporada a iniciativa del ministerio público. Este último, argumentó que: "en las investigaciones preliminares en este tipo de ilícitos es de común ocurencia que sea imposible recabar dicha información, ya que se trata de sujetos que intervienen con apodos, por lo que podría aplicarse el mismo criterio del articulo 154 CPP., en el sentido de estimar suficientes las circunstancias que lo individualicen o determinen"18. Del mismo modo se excluye lo prevenido en

${ }^{17}$ Horvitz, María Inés - López, Julián, Derecho procesal penal chileno (Santiago, Editorial Jurídica de Chile, 2002), I, p. 529.

${ }^{18}$ Historia de la Ley $N^{\circ}$ 20.000: Sustituye la Ley $N^{\circ} 19.366$, que sanciona el tráfico ilícito de estupefacientes y sustancias sicotrópicas (D. O. de 16 de febrero de 2005, p. 597, 
el artículo 167 CPP. relativo a la facultad de archivo del ministerio público. Es decir, aun cuando en estos casos haya existido intervención del juez de garantía, si las diligencias ordenadas no dieren resultado, se permite al fiscal poder archivar provisionalmente la investigación hasta que aparezcan mejores y nuevos antecedentes ${ }^{19}$.

\section{Perspectiva critica: algunas reflexiones.}

En lo que respecta al estándar procesal establecido en la normativa anotada, en particular aquella contenida en el Código Procesal Penal, la escasa doctrina que aborda el tema se encuentra dividida ${ }^{20}$. En efecto, Horvitz y

disponible en: http://www.leychile.cl/Consulta/portada_hl?tipo_norma=XX1\&nro_ ley $=20000 \&$ anio $=2014$

${ }^{19}$ Otros cuerpos normativos referidos a las operaciones de interceptación telefónica son: la Ley $\mathrm{N}^{\circ}$ 19.913: Crea la Unidad de Análisis Financiero y modifica diversas disposiciones en materia de lavado de dinero y blanqueo de activos (D. O. de $18 \mathrm{de} \mathrm{di-}$ ciembre de 2003), incorpora la posibilidad de interceptación telefónica en su artículo 33 letra a), haciendo aplicable la normativa vigente en materia de drogas. Del mismo modo, la Ley $\mathrm{N}^{\circ}$ 20.507: Sobre tráfico de migrantes y trata de personas (D.O. de 8 abril de 2011) agrega el artículo 411 octies CPen. que establece un régimen de técnicas de investigación para los tipos penales que establece la referida ley, sometiéndola también a la regulación existente en materia de droga. Por su parte, la Ley N ${ }^{\circ}$ 19.974: Sobre sistema de inteligencia nacional, (D.O. de 2 de octubre de 2004) permite la intervención de comunicaciones con regulación autónoma en el título $5^{\circ}$, relativo a los procedimientos especiales de obtención de información, en la forma dispuesta por los artículos 24 ss. Por último, la Ley $\mathrm{N}^{\circ}$ 20.393: Establece la responsabilidad penal de las personas jurídicas en los delitos de lavado de activos, financiamiento del terrorismo y delitos de cohecho que indica (D. O. de 2 diciembre de 2009), si bien no contiene una referencia expresa a las operaciones de interceptación de comunicaciones, las mismas resultan procedentes en virtud de la referencia planteada por el artículo 1 inciso $2^{\circ}$ "En lo no previsto por esta ley serán aplicables, supletoriamente, las disposiciones contenidas en el Libro I del CPen. y el CPP. y en las leyes especiales señaladas en el inciso anterior, en lo que resultare pertinente", es decir, hace referencia a la aplicación supletoria tanto del Código Procesal Penal como de la Leyes Nos. 19.913 y 18.314.

${ }^{20}$ En efecto, la manualística procesal penal, en general, al referirse a la materia, sólo se remite a efectuar una relación casi textual de las normas legales, sin que se esbocen puntos críticos al respecto. Véanse: Carocca Pérez, Alex, Manual el nuevo sistema procesal penal ( $3^{a}$ edición, Santiago, LexisNexis, 2005), 289 p.; Cerda San Martín, Rodrigo, Manual del nuevo sistema de justicia criminal (Santiago, Librotecnia, 2005), 642 p.; Cerda San Martín, Rodrigo - Hermosilla Iriarte, Francisco, El código procesal penal. Comentarios, concordancias, jurisprudencia ( $2^{a}$ edición, Santiago, Librotecnia, 2006), 870 p.; Correa Selamé, Jorge, Curso de derecho procesal penal (Santiago, Ediciones Jurídicas de Santiago, 2003), 398 p.; Duce, Mauricio - Riego, Cristián, Introducción al nuevo sistema procesal penal (Santiago, Ediciones Universidad Diego Portales, 2002), I, 360 p.; Hermosilla Arriagada, Germán, Nuevo procedimiento penal ( $2^{\mathrm{a}}$ edición, Santiago, Ediciones Universidad Central, 2005), II, 210 
Lópe $z^{21}$ estiman que "se trata de uno de los pocos casos en que el legislador se preocupó de establecer requisitos claros de procedencia de una medida intrusiva, configurando un estándar bastante exigente"22. Para arribar a esta conclusión tienen a la vista la referencia que la norma efectúa a la existencia de sospechas fundadas, basada en hechos determinados, respecto de hechos que merezcan pena de crimen y siempre que la investigación lo haga imprescindible. Señalan que esta última "es lo que la doctrina denomina principio de intervención mínima o de subsidiariedad, derivaciones del principio de prohibición de exceso, que imponen rechazar las medidas cuyo fin pueda ser alcanzado por otras menos gravosas" ${ }^{\prime 2}$.

p.; Maturana Miquel, Cristián - Montero López, Raúl, Derecho procesal penal (Santiago, Editorial Abeledo Perrot, 2012), II, 1146 p.; Medina Jara, Rodrigo - Morales Palacios, Luis - Dorn Garrido, Carlos, Manual de derecho procesal penal (Santiago, LexisNexis, 2005), 317 p.; Ministerio Público, Fiscalía Nacional, Reforma procesal penal, Instrucciones generales $N^{\circ} 1$ a 25, septiembre-noviembre 2000 (Santiago, Editorial Jurídica de Chile, 2000), 442 p.; NúÑ̃z VÁsQuez, Juan Cristóbal, Tratado del proceso penal y del juicio oral (Santiago, Editorial Jurídica de Chile, 2002), II, 581 p.; Ortíz Schindler, Enrique - Medina Ramírez, Marco Antonio, Manual del nuevo proceso penal (Santiago, Librotecnia, 2005), 325 p.; Pfeffer Ureuiaga, Emilio, Código procesal penal. Anotado y concordado (2a edición, Santiago, Editorial Jurídica de Chile, 2006), 825 p.; Tavolari Oliveros, Raúl, Instituciones del nuevo proceso penal. Cuestiones y casos (Santiago, Editorial Jurídica de Chile, 2005), 440 p. Salvo el trabajo de PASTÉn PÉREZ, tampoco es posible encontrar artículos especializados sobre el punto.

${ }^{21}$ Horvitz, María Inés - López, Julián, cit. (n. 17), p. 528.

${ }^{22}$ Chahuán Sarrás, Sabas, Manual del nuevo procedimiento penal (2a edición, Santiago, LexisNexis, 2002), p. 206. Define como “exigente” el estándar fijado para la procedencia de la medida, pero no especifica los motivos de tal conclusión. La juez de garantía doña María Francisca Zapata García y actual Vicepresidenta de la Asociación Nacional de Magistrados de Chile, califica de "exhaustiva" la reglamentación efectuada por el Código, por señalar quiénes pueden ser afectados por la medida, bajo qué circunstancias y de qué forma. Sin embargo, igualmente se limita a reproducir la norma en el sentido de indicar que su procedencia debe ser analizada por el juez sobre la base de los antecedentes que el fiscal le presente, debiendo constatar que existen fundadas sospechas, basadas en hechos determinados, de que la persona que será afectada con la medida haya cometido o participado en la preparación o comisión, o que prepare actualmente la comisión o participación en un hecho punible que merezca pena de crimen y siempre que la investigación lo haga imprescindible. Señala que si bien este estándar deberá ser fijado en su grueso por los jueces al tener que decidir en cada caso si las sospechas que se invocan son fundadas y si la investigación hace imprescindible esta medida; a su juicio, de todos modos, la ley da un contenido primario al determinar que se debe tratar de ilícitos de una determinada gravedad: crímenes. Véase: Zapata García, María Francisca, La prueba ilícita (Santiago, LexisNexis, 2004), pp. 82 s.

${ }^{23}$ Horvitz, María Inés - López, Julián, cit. (n. 17), p. 529. El espaciado es del texto extractado. 
Desde otra perspectiva, Weezel y Darricades distinguen: por una parte, el carácter restrictivo con que aparecen descritos los requisitos de procedencia de la medida sobre el papel y por otra, el modo en que ellos son aplicados en la práctica ${ }^{24}$. Señalan que: "el examen de estos presupuestos permite advertir, sin embargo, que la técnica legislativa empleada es precaria en la delimitación precisa de su contenido". Agregan que: "los problemas más preocupantes tienen que ver con el juicio de mérito sobre el carácter 'imprescindible' de la medida, así como de la presencia o no de 'fundadas sospechas basadas en hechos determinados"'. Sobre todo si se tiene presente que, legalmente, para decidir la procedencia de la medida, no existe obligación de revisar la totalidad de los antecedentes de la investigación. Así, a propósito de la necesidad de desarrollar criterios para un control racional del instituto, los citados autores son conscientes que el rodaje de la reforma, fue apagando el espíritu crítico de los esfuerzos jurisprudenciales iniciales ${ }^{25}$.

No obstante lo dicho, lo cierto es que la doctrina procesal penal chilena no ha reparado en el estudio de la motivación del decreto judicial que autoriza la interceptación, con la fuerza que merita. El panorama jurisprudencial es igualmente asolado. Tanto es así, que el Instructivo $\mathrm{N}^{\circ} 16$ del año 2000 elaborado por el ministerio público, al referirse a la motivación como requisito de fondo de la resolución judicial autorizante señala que, no obstante las normas del Código no hagan una alusión explícita a este requisito, "sería conveniente que la orden en cuya virtud se lleva a cabo esta medida, debiera ser motivada, ello con el fin de que el interesado pueda en su momento conocer con precisión cuáles fueron los motivos que originaron la intervención y así poder resguardar debidamente sus derechos"26.

${ }^{24}$ Con todo, legalmente no se especifica el contenido de un decreto motivado. En Italia, la cuestión gozaba de mayor determinación bajo la vigencia del antiguo Código de 1930. Como señala Illuminati, Giulio, La disciplina processuale delle intercettazioni (Milano, Giuffrè, 1983), p. 96: "Quanto al suo contenuto, la legge ora ne indica specificamente i requisiti minimi, sia pure con una disposizione -l'artículo 226-ter comma $1^{\circ}$ c.p.p.- che, come si è visto, non è priva di ambiguità. In ogni caso la motivazione dovrà dar conto dell'esistenza di una notizia di reato conforme alle ipotesi elencate nell'artículo 226-bis c.p.p., e degli indizi (prove) al riguardo, «da indicarse specificamente nel decreto». Dovrà inoltre indicare gli obiettivi che in concreto si intendono perseguire: se non è errata l'interpretazione che si suggeriva circa le finalità stabilite dalla legge, si tratterà, in particolare, di precisare quali elementi probatori si ritiene di ottenere. La motivazione dovrà, infine, spiegare le ragioni che rendono necessario, nel caso specifico, ricorrere all'intercettazione, nei confronti dell'indiziato e del terzo".

${ }^{25}$ WeEzel van, Alex - Darricades, Tomás, Interceptaciones telefónicas. Oportunidad para avanzar, en Revista del Abogado del Colegio de Abogados de Chile, 52, (julio de 2011), pp. 40-43.

${ }^{26}$ Ministerio Público, Fiscalía Nacional, Reforma procesal penal. Instrucciones generales 
El aludido instructivo, a propósito del criterio de proporcionalidad, dota de contenido a las llamadas "sospechas fundadas" haciendo referencia a la sentencia de 8 de febrero de 1997 del Tribunal Supremo español ${ }^{27}$. Si bien concibe como "sospechas fundadas", los datos objetivos que sean conocidos y valorados por el propio juez y no sólo por la Policía o el ministerio público, y con ello descarta las denominadas "escuchas predelictuales o de prospección”, y la posibilidad de decretar una interceptación telefónica para tratar de descubrir actos delictivos en general, sin la adecuada precisión ${ }^{28}$; la realidad práctica de la aplicación de la medida parece decir otra cosa. Aunque se carece de datos estadísticos oficiales, el número de solicitudes diarias de interceptación telefónica y, el número de casos en que la medida es concedida, evidencia una situación -si no alarmante-, al menos preocupante.

Weezel y Darricades inician sus comentarios aludiendo a la existencia de cerca de 80 solicitudes diarias. El Centro de Investigación Periodístico de Chile ${ }^{29}$ en un artículo publicado el 29 de octubre de 2008 señala que al menos 5 interceptaciones telefónicas se ordenan cada día en Santiago. En lo pertinente indica que: "Desde mediados de año, cuando se anunció que la investigación contra la banda de narcotraficantes 'Los Cavieres' acumuló 50 mil grabaciones telefónicas, ya ninguna cifra sorprende. Las indagaciones por la recientemente descubierta red de corrupción vinculada a la policía y al sector judicial sumaron otras 17 mil. Y unas 5 mil han resultado de las gestiones para dar con las redes de estafadores que actúan mediante contactos telefónicos. Las cifras son exorbitantes, pero no dan cuenta del número de teléfonos que fueron intervenidos en cada caso" ${ }^{\text {"30 }}$.

La ausencia de fuentes oficiales de información implica un obstáculo para el análisis del fenómeno tanto desde el punto de vista científico como periodístico. En efecto, el mencionado Centro señala que: "[...] en el ministerio público no disponen de un registro de solicitudes a los juzgados del país. En tanto, en la asociación de compañías de teléfonos celulares se

$N^{\circ} 1$ a 25, cit. (n. 20), p. 271. El expandido es nuestro. La utilización de la expresión "conveniente" confirma la escasa relevancia que la ley y el debate jurídico otorgan a esta "exigencia".

${ }^{27}$ Ibíd., p. 272.

${ }^{28}$ Ibíd., p. 284. Esto es lo que el instructivo denomina requisito de "especialidad de la materia a investigar, en el sentido que no cabe disponer la interceptación para lograr el descubrimiento genérico de posibles delitos, situación que supondría conceder autorizaciones en blanco".

${ }^{29}$ Es una organización chilena sin fines de lucro que se constituye como medio de información en línea desde noviembre del año 2007. Se define como un medio alternativo e independiente, que se ha destacado por el alto impacto social de sus publicaciones.

${ }^{30}$ Centro de Investigación Periodístico de Chile, disponible en http://ciperchile. d/2008/10/29/asi-se-hacen-los-cuestionados-pinchazos-telefonicos-legales. 
niegan a entregar cifras oficiales. Y en el ámbito judicial, de los 21 juzgados de garantías de la Región Metropolitana consultados por el Centro, respondieron 14. La suma reportada por estos últimos da una idea aproximada de la magnitud del fenómeno: durante el primer semestre de 2008, estos catorce juzgados despacharon más de mil autorizaciones. Es decir, más de 5 interferencias telefónicas diarias" ${ }^{\prime 31}$. Más recientemente, otro medio periodístico electrónico, publicó con fecha 8 de abril de 2013, que cifras del ministerio público, obtenidas a través de la llamada "Ley de transparencia", muestran que durante el año 2012 fueron autorizadas un total de 12.498 interceptaciones. El informativo expresa que dichos antecedentes muestran que, en promedio, durante el 2012, se efectuaron 34,2 escuchas telefónicas diarias, y 1.041,5 al mes, en todo Chile. Se precisa, también, que en 2012 la fiscalía solicitó 12.640 diligencias de este tipo, de las que 142 fueron rechazadas por no cumplir con los requisitos formales estipulados por el sistema ${ }^{32}$. Teniendo en cuenta que una operación de interceptación supone inmiscuirse en el contenido de una conversación que involucra al menos dos sujetos, el número de personas afectadas por las mismas debiese fijarse en 24.996, ello sin considerar que la información alude al número de causas en que las medidas fueron autorizadas y no al número de aparatos ni al número de personas sometidas a intervención en cada causa.

Atendido a que la ley no faculta la concesión de autorizaciones en blanco, las cifras anotadas sólo pueden conducirnos a una de dos conclusiones: $i$ ) nos encontramos frente a un aumento explosivo de delitos cuya eficaz persecución ha de cuestionarse necesariamente; o bien, ii) nos hallamos frente a una aplicación en extremo descuidada de la hipótesis de procedencia de la medida.

Si bien la falta de un seguimiento sistemático oficial impide formular un análisis estadístico y sustancial en orden a una aplicación descuidada de los presupuestos de la norma, dicha conclusión es de todos modos forzosa. En efecto, un eventual aumento explosivo de criminalidad susceptible de operaciones de interceptación, debe ser descartado de acuerdo a los informes estadísticos anuales del ministerio público ${ }^{33} \mathrm{y}$ al universo de causas en que la medida ha sido concedida durante el 2013. Además, los escasos pronunciamientos de nuestros tribunales superiores -a los que se hará alusión en el presente trabajo-, dan cuenta de la falta de rigurosidad en la aplicación de las interceptación telefónica.

${ }^{31}$ CIPER Chile, cit. (n. 31)

32 Información disponible en: http://www.latercera.com/noticia/ nacional/2013/04/680-517674-9-fiscalia-34-escuchas-telefonicas-diarias-serealizaron-en-promedio-en-2012.shtm

${ }^{33}$ Disponibles en: http://www.fiscaliadechile.cl/Fiscalia/estadisticas/index.do 
Para arribar a la respuesta, en el marco del presente trabajo, se hizo uso de la facultad de requerir información merced a la "Ley de transparencia" ${ }^{44}$. Así, de acuerdo a los datos del ministerio público, "durante el año 2013 hubo un total de 19.428 solicitudes de interceptación telefónica, debidamente autorizadas, y que corresponden a un total de 1912 investigaciones o RUC; de lo que podríamos señalar que hay un promedio de 10,16 solicitudes por investigación". Sin embargo, también señalan que se encuentran imposibilitados de otorgar información en torno al número de solicitudes efectuadas por el ministerio público ya que carecen de registro de solicitudes de las diversas fiscalías locales, disponiendo de información exclusivamente de las órdenes obtenidas. Al referirse al número total de solicitudes autorizadas, no hay precisión sobre el número de aparatos/números de teléfono afectados. Si bien contamos con un número representativo del universo de causas en que la medida ha sido ordenada (a diferencia de la información publicada por los medios electrónicos aludidos), continuamos desconociendo el destino final de dichas causas, por lo que resulta imposible proyectar la efectiva productividad del uso de la herramienta.

En este sentido compartimos los dichos que el profesor Jorge Bofill efectuara en el contexto del citado informe periodístico: "el problema va más por el lado del criterio de quienes aplican la herramienta, que de la herramienta misma [...] en general, los jueces están siendo un poco laxos en otorgar permisos de interceptación, y poco prolijos en evaluar si el hecho investigado es constitutivo o no de materia de delito" ${ }^{35}$. Esta laxitud radica en el análisis fáctico de las circunstancias objetivas que autorizan la concesión de la medida, unida a la falta de la debida fundamentación al dar por establecidos los restantes requisitos de procedencia. Ejemplo de ello es el caso analizado en el fallo rol N ${ }^{\circ} 3016-2011$, de la Corte Suprema, de 29 de junio de 2011, que rechaza un recurso de nulidad interpuesto por la defensa en contra de la sentencia del $6^{\circ}$ Tribunal Oral en lo Penal de Santiago, por la causal del artículo 373 letra a) CPP.

El vicio denunciado ilustra una cuestión de frecuente ocurrencia. Los antecedentes puestos a disposición del ministerio público por la policía, para la respectiva tramitación de la autorización de la medida de interceptación telefónica por la posible comisión de una infracción a la Ley $\mathrm{N}^{\circ} 20.000$, se basó en el contenido del parte denuncia del siguiente tenor "en virtud al análisis sistemático de información y perfiles utilizados en la comisión de ilícitos contemplados en la Ley $\mathrm{N}^{\circ} 20.000$, recopilados por medio de las

\footnotetext{
${ }^{34}$ Carta del Director Ejecutivo Nacional, Ley de Transparencia, $\mathrm{N}^{\circ} 336 / 2014,29$ de agosto de 2014, Solicitud N 928.

${ }^{35}$ Centro de Investigación Periodístico de Chile, cit. (n. 30)
} 
continuas investigaciones antinarcóticos que ha desarrollado esta Brigada Especializada, se desprende la presunción en la comisión de un nuevo delito" ${ }^{36}$. Con dichas afirmaciones, carentes de toda determinación, se autorizó la medida de interceptación, estableciéndose con posterioridad que las mismas obedecían a información recabada a través de interceptaciones ejecutadas sin autorización judicial alguna (registros que, no obstante la solicitud de la defensa, no fueron excluidos en la audiencia de preparación respectiva).

Si bien la Corte refrenda la conculcación al derecho fundamental de la inviolabilidad de las comunicaciones respecto de las interceptaciones no autorizadas, considera que tal infracción no es suficiente para acoger el recurso, por cuanto las mismas no fueron fundamento de la condena impugnada. Lo relevante del fallo comentado es que sobre las restantes interceptaciones autorizadas judicialmente no extiende la ilicitud que arguye la defensa, porque en su opinión "síbubo un inicio genuino en el procedimiento policial, una denuncia realizada en un procedimiento distinto y con su mérito, igual se habria recibido el consentimiento para la interceptación telefónica de las llamadas que si tenian valor para el establecimiento del hecho y de la participación de la encartada" ${ }^{37}$. Más allá de que se adhiera o no a la llamada teoría de los frutos del árbol envenenado, a la prueba ilícita derivada o a la excepción de descubrimiento inevitable, el supuesto origen genuino en que funda la licitud, demuestra el deficiente estándar con que la medida es autorizada en la práctica. En efecto, el fallo salva la ilicitud a partir de la referencia que el parte denuncia efectúa a "antecedentes residuales de otras investigaciones", cuestión que, según la Corte Suprema, habría quedado zanjada con la declaración de uno de los oficiales en el juicio oral al indicar que "la investigación comenzó por una denuncia realizada en una causa aparte" ${ }^{38}$. Por inverosímil que parezca no hay mayores especificaciones ni detalles en la información y tampoco se analiza la atendibilidad de la fuente, esto es, no se descarta que dicha declaración obedezca a uno de los policías involucrados en las escuchas ilegales, y en su caso el por qué en este caso el mismo debiese considerarse razonablemente creíble.

Así, en el presente trabajo se sostiene que cualquier intento por corregir este tipo de razonamientos demanda precisar el contenido de dichos requisitos, en particular la determinación conceptual y empírica de las llamadas "fundadas sospechas". En general, la doctrina chilena no desarrolla el contenido de esta expresión. En términos sucintos, Núñez Vásquez entiende que por tales se hace alusión a "presunciones razonables cimentadas en sucesos

\footnotetext{
${ }^{36}$ Sentencia de la Corte Suprema, $2^{a}$ Sala, causa rol $N^{\circ} 3016-2011$, considerando $6^{\circ}$.

${ }^{37}$ Ibíd., considerando $6^{\circ}$, parte final.

${ }^{38}$ Ibíd., considerando $6^{\circ}$.
} 
precisos y concretos, de que una persona ha cometido o participado en la preparación, o se encuentre preparando la comisión o participación en un hecho punible que mereciere la pena de crimen, y la investigación le hiciere imprescindible ${ }^{39}$. Tal afirmación debiese complementarse con la acertada precisión de Horvitz y López en orden a que debiese tratarse de hechos constitutivos de actos preparatorios actualmente punibles ${ }^{40}$. Recalcar esta circunstancia no es baladí. De hecho, Chahuán Sarrás señala que: "esta es la única medida que puede ser utilizada a u n a n te s de la comisión de un hecho delictivo" "41 , cuestión que no se condice con el carácter excepcional de esta medida. Como explica López de Quiroga, no debe ser "la escucha la que dé lugar a la formación de la 'causa', sino que por el contrario la «causa» debe existir, estar en tramitación y apreciarse de la misma que con la escucha es posible obtener el descubrimiento o la comprobación de algún hecho relevante para la 'causa"'‘2. La práctica judicial chilena no puede estar más alejada de esta consideración ${ }^{43}$.

En un análisis más exhaustivo, Pastén Pérez explica que el juez de garantía debe analizar los hechos en los que se funda la solicitud del ministerio público, y determinar si de ellos se extraen conclusiones lo suficientemente categóricas que le hagan sospechar de que el imputado ha tenido algún tipo de participación en el crimen investigado. A su juicio, este último extremo implica que el juez le otorgue cierta credibilidad a tales circunstancias fácticas,

${ }^{39}$ NúÑEZ VÁsQueZ, Juan Cristóbal, cit. (n. 19), pp. 83 s.

${ }^{40}$ Refiriéndose a los sujetos que pueden ser afectados por la medida, los autores señalan: "La redacción de este precepto es poco afortunada. En efecto, pareciera referirse no sólo a las personas a quienes se impute, en calidad de autor o partícipe, un delito consumado que merece pena de crimen sino también a quien realice cualquier etapa previa de comisión del mismo, incluidos los actos preparatorios. Sin embargo, debe recordarse que los actos preparatorios de un delito son punibles sólo excepcionalmente (artículo $8^{\circ} \mathrm{CP}$ ). En consecuencia, no procederá esta medida si el hecho que se quiere pesquisar no es actualmente punible y no merece pena de crimen”. HorviTz, María Inés - LóPEZ, Julián, cit. (n. 17), p. 528. En el mismo sentido PASTÉN PÉREZ, Dagoberto, cit. (n. 12), p. 72, quien en relación a la hipótesis prevista en el c.p.p. señala: "ahora bien, cualquiera sea el hecho punible investigado, siempre deberá versar sobre crímenes consumados (o bien, en grado de tentativa o frustración) y excepcionalmente respecto de actos preparatorios de dichos hechos punibles, al contrario de lo pretendido por el artículo 222 inciso $1^{\circ}$ cuando dispone que la medida procede incluso cuando el afectado "prepare actualmente la comisión o participación en un hecho punible", por cuanto ello dependerá de que dichos actos preparatorios estén sancionados expresamente en la ley, y que respecto de los mismos, proceda la pena de crimen". La cursiva es de la cita.

${ }^{41}$ Chahuán SARrás, Sabas, cit. (n. 22), p. 206. El expandido es nuestro.

${ }^{42}$ López de Quiroga, Jacobo, cit. (n. 1), p. 193.

${ }^{43}$ Ahondaremos en este punto con ocasión del estudio de la situación de la notificación del afectado. 
cuestión que debiese tener lugar siempre que ellas sean lógicas y verosímiles, de tal manera que permitan al juez de garantía concluir la probabilidad de que el imputado ha tenido algún tipo de participación en el hecho investigado ${ }^{44}$. No obstante lo indicado, parece conveniente ahondar sobre el punto, en modo de poder ofrecer al juez un panorama claro del estándar de convicción que requiere la aplicación de la medida. Así, para dilucidar la cuestión resulta oportuno efectuar dos indicaciones.

En primer lugar, debe tenerse presente que la expresión "sospechas fundadas" es utilizada en el Código únicamente en el artículo 222 sobre interceptación telefónica. En segundo lugar, es posible encontrar expresiones relativamente afines, con ocasión de dos materias: i) en los artículos 85 y 89 , relativo al control de identidad y examen de vestimentas, respectivamente. Ambas disposiciones utilizan el vocablo "indicio". Más precisamente, la primera disposición, en lo pertinente, señala que los funcionarios policiales deben, sin orden previa de los fiscales, solicitar la identificación de cualquier persona "en los c a s os fundados, en que, según las circunstancias, estimaren que existen in $\mathrm{d}$ i c i o s de que ella hubiere cometido o intentado cometer un crimen, simple delito o falta; de que se dispusiere a cometerlo; y $i i$ ) en el artículo 140 referido a los requisitos para ordenar la prisión preventiva. Por una parte, los llamados "presupuestos materiales" contenidos en las letras a) y b) del precepto, requieren, respectivamente, antecedentes que justificaren la existencia del delito investigado, y antecedentes que permitieren presumir fundadamente que el imputado ha tenido participación en el delito como autor, cómplice o encubridor. En otras palabras, antecedentes basados en hechos ciertos y determinados que den sustento a una presunción fundada. Luego, la letra c) consagra el denominado requisito de "necesidad de cautela", esto es, nuevamente, antecedentes calificados que permitieren al tribunal considerar que la prisión preventiva es in d is pe n s able para el éxito de diligencias precisas y determinadas de la investigación, o que la libertad del imputado es peligrosa para la seguridad de la sociedad o del ofendido, o que existe peligro de que el imputado se dé a la fuga, conforme a las disposiciones de los incisos siguientes. Se trata de la consagración del principio de excepcionalidad y de instrumentalidad propio de las medidas cautelares personales en general. "El principio de excepcionalidad afirma que las medidas cautelares no son medidas que necesariamente deban adoptarse dentro del procedimiento, sino que tienen un carácter eventual: deben decretarse sólo cuando resulten indispensables; el principio de instrumentalidad, por su parte, califica dicha excepcionalidad, determinando que ellas no constituyen un fin por sí mismo,

${ }^{44}$ PAStÉn PÉREZ, Dagoberto, cit. (n. 12), pp. 78 s. 
sino que son instrumentales: están orientadas a la consecución de fines de carácter procesal" ${ }^{35}$.

Dicho lo anterior, corresponde efectuar una mirada histórica y de conjunto, para nutrir de contenido la hipótesis de procedencia de la medida de interceptación y establecer, por ende, aquello que debiese exigirse a la función jurisdiccional en su deber de motivación. Hemos señalado que la Ley $\mathrm{N}^{\circ}$ 18.314: Sobre conductas terroristas, prevé en su artículo 14, la posibilidad de solicitar la medida de interceptación de las comunicaciones del imputado por alguno de los delitos contenidos en el artículo 1 de dicha ley. Esta opción es prevista sólo una vez que se haya formalizado la investigación en contra del imputado. Aún más, el sólo planteamiento de la solicitud se encuentra expresamente condicionado a que sea procedente la prisión preventiva del imputado. Si bien la extensión de este trabajo no permite detenernos sobre el alcance de este último requisito, sí es suficiente para efectuarnos la siguiente pregunta: ¿cómo es posible entonces, que el estándar de procedencia y motivación de la resolución autorizante, en una etapa procesal previa a la formalización de la investigación en contra de un ciudadano pueda ser inferior al aquí consagrado?

Hemos tenido ocasión de dejar constancia del vuelco legislativo que el proyecto de reforma procesal tuvo en el Parlamento. Conviene traer a colación uno de los argumentos utilizados para evitar la eliminación de la figura, cual es, el hecho que "todas las medidas cautelares y todas las medidas de investigación afectaban derechos individuales, e invadian distintos ámbitos de privacidad". De ello resulta entonces que, no es descabellado pensar en la extensión de las garantías que revisten las medidas cautelares a aquellas medidas intrusivas de investigación que, por su carácter, producen el mismo efecto: afectar derechos fundamentales del individuo. Aún más, la premisa ha de ser la siguiente: si la solicitud de medidas cautelares, en general, requiere de la formalización de la investigación en contra del imputado; toda pretensión de afectar derechos fundamentales en forma previa ha de revestir mayores exigencias. Tal como se deduce de la regulación de las interceptación telefónica en materia de terrorismo.

En estrecha relación con lo anterior, se encuentra otro interesante antecedente histórico legislativo, esta vez en la introducción de la figura de interceptación en la Ley $N^{\circ}$ 19.366: Sobre tráfico de drogas. La precisión efectuada por el entonces ministro de Justicia don Francisco Cumplido Cereceda, en orden a que las "fundadas sospechas" debían entenderse referidas al artículo 252 del Código de Procedimiento Penal para detener a una persona. Luego, el artículo 255 relativo a los presupuestos para que el juez que instruye un

\footnotetext{
${ }^{45}$ Horvitz, María Inés - López, Julián, cit. (n. 17), p. 352.
} 
sumario pueda decretar la detención, en su numeral $1^{\circ}$ señala que tal facultad procede cuando, estando establecida la existencia de un hecho que presente los caracteres de delito, el juez tenga $\mathrm{fun} \mathrm{d}$ a $\mathrm{d}$ a s $\mathrm{s}$ o $\mathrm{s}$ pe $\mathrm{ch}$ a s para reputar autor, cómplice o encubridor a aquel cuya detención se ordene. Es decir, bajo la óptica de la reforma, la referencia se encuentra hecha - una vez más- a los presupuesto de procedencia de la prisión preventiva. El modelo esbozado cobra sentido con la aclaración que el Ministro de Justicia formulara a continuación: "la diferencia es que, en esta situación, no se materializa la detención con el propósito de seguir la red de tráfico" ${ }^{46}$. Se trata de un punto sin duda interesante para devolver el verdadero ámbito operacional y funcional de la figura.

Por último, otro dilema por dilucidar está constituido por la precisión empírica de las llamadas "fundadas sospechas". Es claro que los antecedentes de hecho que se pongan a la base de la solicitud de interceptación telefónica pueden ser de la más diversa naturaleza, de modo que es ilusorio concebir un detalle en términos positivos en tal sentido. Sin embargo, ello no impide reclamar la necesidad de zanjar - desde una determinación en términos negativos- el recurso a las llamadas informaciones anónimas, como instrumento de casi absoluta frecuencia en las labores de inteligencia de las policías ${ }^{47}$. En Italia, bajo la vigencia del Código de 1930, la sentencia $N^{\circ} 34$ de la Corte Constitucional de 6 de abril de $1973^{48}$, ya ponía énfasis en la argumentación sobre la base de elementos de hecho, tanto para evitar alusiones genéricas a la conveniencia y oportunidad de la medida, como por sobre todo, para evitar consideraciones relativas a denuncias provenientes de confidentes anónimos de la policía, sin que en nada obstara a estos lineamientos la eventual verificación de resultados positivos luego de su ejecución (juicio ex-ante) ${ }^{49}$.

${ }^{46}$ Historia de la Ley $N^{\circ} 19.366$, cit. (n. 8), p. 422.

${ }^{47}$ Una posición clara a su respecto es de fundamental importancia si se tiene presente que desde el 16 de noviembre de 2010, el entonces ministro del Interior Rodrigo Hinzpeter Kiberg, lanzó oficialmente el programa "Denuncia seguro", cuyo principal compromiso es el anonimato de las personas que llaman para denunciar. En efecto, no se pregunta su identidad, ni se requiere entregar ningún antecedente personal. Tampoco queda registro alguno del número desde el cual se genera la llamada y las conversaciones no son grabadas. Sitio web disponible en: http://www.denunciaseguro.cl/ preguntas.htm

${ }^{48}$ Anális de sentencia en Grevi, Vittorio, Insegnamenti, moniti e silenzi della Corte Costituzionale in tema di intercettazioni telefoniche, en Giurisprudenza costituzionale (1973), pp. 316-342.

${ }^{49}$ Véase también, Grevi, Vittorio, Appunti, cit. (n. 2), p. 735. Analiza el fallo del Tribunal de Roma en sesión I, de 10 de noviembre de 1966, donde los sentenciadores denuncian un estado de perplejidad al advertir que la solicitud de interceptación y la respectiva motivación del decreto, se basaban en el contenido de una denuncia recibida 
Hoy, en el marco del Código de 1988, "en la valoración de los graves indicios de delito se aplica el artículo 203; es decir, si los indicios se basan en declaraciones confidenciales de informantes de la policía, las declaraciones mismas pueden ser utilizadas sólo cuando los informantes han sido examinados como testigos o como personas informadas sobre los hechos y, por tanto, cesan de ser anónimos. Si los informantes no han sido examinados, sus declaraciones no pueden ser utilizadas a efectos de valorar la gravedad de los indicios del delito" 50 .

En nuestro medio, la argumentación debiese estructurarse sobre la base de la garantía del debido proceso, el cual supone el derecho del imputado a confrontar a su acusador, cuestión que no puede ejercerse tratándose de informaciones anónimas. Por lo demás, desde el punto de vista de la valoración del elemento probatorio con que se pretenda llevar tal información a juicio, esto es, a través de la declaración de un funcionario de policía, dicha hipótesis tampoco permite efectuar un análisis de atendibilidad de la fuente de prueba ni de la credibilidad de dicha declaración por lo que la garantía en cuestión quedaría completamente suprimida. No debe perderse de vista que la recepción de tales informaciones ni siquiera cumple con los requisitos establecidos en el artículo $174 \mathrm{CPP}$. para ser considerada denuncia en términos técnicos y por ende, la falta de garantías que la caracteriza no puede servir de base para la afectación de un derecho fundamental. En definitiva se trata entonces de distinguir entre sospechas fundadas y sospechas policiales ${ }^{51}$.

\section{ACTUAL NORMATIVA SOBRE CONTROL EXTERNO} EN MATERIA DE INTERCEPTACIÓN TELEFÓNICA: CONTROL JURISDICCIONAL Y NOTIFICACIÓN DEL AFECTADO COMO PRESUPUESTO DEL MISMO

\section{Sanción en el evento de infracción al deber de motivación.}

El artículo 225 CPP., titulado "Prohibición de utilización", dispone que: "Los resultados de la medida de interceptación telefónica o de otras formas

por la policía judiciaria en vía confidencial. Si bien el sistema procesal italiano "reconoce a la policía judiciaria la posibilidad de valerse de informaciones adquiridas a través de confidentes, sea para el 'descubrimiento' de delitos, sea para el sucesivo desarrollo de las investigaciones, ello no significa que una denuncia de tal origen baste para justificar, por sí sola, el cumplimiento de cualquier acto de policía, sobre todo si se trata de un acto para el cual es requerida la autorización del magistrado". La traducción es nuestra.

${ }^{50}$ Tonini, Paolo, Manuale di procedura penale (11 a edición, Milano, Giuffrè, 2010), p. 381.

${ }^{51}$ Cfr. resolución de juez de garantía de Coquimbo María Francisca Zapata, RUC 0400018814-5, RIT 213-2004, disponible en Revista Jurídica del Ministerio Público, 20 (septiembre de 2004), pp. 11-13, en materia de autorización de entrada y registro. 
de telecomunicaciones no podrán ser utilizados como medios de prueba en el procedimiento, cuando ella bubiere tenido lugar fuera de los supuestos previstos por la ley o cuando no se hubieren cumplido los requisitos previstos en el articulo 222 para la procedencia de la misma". No obstante la aparente claridad en la redacción de esta norma, la doctrina nacional no es unívoca en la identificación de la sanción que ella consagra. Las posibilidades son dos: determinar la aplicación del régimen procesal de la nulidad (artículos 159 ss. CPP.); o bien establecer si se trata de un caso de exclusión de prueba por infracción de garantías constitucionales (artículo 276 CPP.).

Por una parte, un sector de la doctrina reproduce el texto legal y, se refiere simplemente al efecto, es decir, a la inutilización de la prueba obtenida, pero no identifica el régimen jurídico sancionatorio aplicable ${ }^{52}$. Los profesores Duce y Riego, en cambio, toman posición, y señalan que: "para realizar alguna de estas diligencias, el ministerio público siempre requerirá autorización judicial previa, ya que, en caso contrario, el resultado de las mismas será nulo y no podrá ser presentado al juicio oral" ${ }^{\text {"3 }}$. Carocca Pérez, por su parte, señala que ambas hipótesis del artículo $225 \mathrm{CPP}$. dan lugar a la facultad del juez de garantía de excluir aquellas pruebas que hubieren sido obtenidas con inobservancia de garantías fundamentales en conformidad con lo dispuesto en el artículo 276 del mismo cuerpo legal ${ }^{54}$.

En una tercera posición, se ubican las anotaciones de Chahuán Sarrás y Horvitz/López. El primero, indica que: "esta prohibición podría reclamarse por la vía de solicitar la nulidad procesal de la actuación -artículos 159 a 165 CPP.- en la audiencia de preparación del juicio oral, invocando el artículo 276 CPP. para excluirla como prueba. Amén de ello, no se puede olvidar el recurso de nulidad aunque su procedencia, en esta hipótesis, resulta asaz discutible" 55 . Es decir, parece ser de la opinión que serían aplicables ambos regímenes procesales sancionatorios, en cualquiera de las hipótesis que con-

${ }^{52}$ Hermosilla Arriagada, Germán, cit. (n. 20), p. 153: "Es importante tener presente que los resultados de la medida de interceptación telefónica o de otras formas de telecomunicaciones no podrán ser utilizados como medios de prueba en el procedimiento, cuando ellas hubieren tenido lugar en otra forma que la autorizada en conformidad a las reglas precedentes".

${ }^{53}$ Duce, Maurici - Riego, Cristián, cit. (n. 20), p. 138.

${ }^{54}$ Carocca Pérez, Alex, cit. (n. 20), p. 141 s. Trata el punto con ocasión de las diligencias de investigación prohibidas, donde señala que: "En definitiva, se ha estimado la improcedencia absoluta de estas diligencias, por la gravedad que puede significar la privación, restricción o perturbación de derechos que la Constitución asegura a las personas, a fin de proteger la autonomía, intimidad y la dignidad de las personas en su esfera privada. Por cierto, cualquier otra diligencia capaz de afectar estos derechos de la misma manera, también será considerada ilegítima e inconstitucional”.

${ }^{55}$ Chahuán Sarrás, Sabas, cit. (n. 22), p. 207. 
tiene el artículo 225 CPP. Sin embargo, no ahonda sobre las repercusiones de una u otra opción. Aunque no lo señalan expresamente, Horvitz y López, también parecen sustentar esta dualidad, pero diferenciando los supuestos del artículo 225 CPP. Estos últimos, introducen una distinción en la lectura de la norma, según se trate de prueba obtenida fuera de los casos previstos por la ley; o, de prueba obtenida con incumplimiento de los requisitos legales. Indican que: "la primera hipótesis constituye uno de los pocos casos en que la ley regula expresamente los efectos de la prueba obtenida ilícitamente, la que puede ser excluida del procedimiento en la etapa de preparación del juicio oral. La segunda hipótesis se refiere exclusivamente a la inobservancia de los requisitos de procedencia de la medida, esto es, aquellos que se refieren al estándar de antecedentes de investigación y al tipo de delito investigado. [...] Pareciera que la mayor rigurosidad de la regulación en este caso [...] dice relación con el grado de mayor intensidad de afectación del derecho fundamental a la intimidad" 56 .

Esta encrucijada forma parte de un tema mucho más amplio, complejo y discutido, conocido en nuestro medio como "prueba ilícita". Por razones obvias, atendida la entidad de la materia en discusión, si bien no podemos detenernos en un análisis exhaustivo, es necesario efectuar un par de consideraciones. En primer lugar, es conveniente destacar que la indeterminación, en abstracto, del régimen sancionatorio aplicable al incumplimiento de la normativa que regula la interceptación telefónica, resulta a todas luces, una grave afectación al derecho de defensa. Las deficiencias del sistema de control interno, jamás podrán ser adecuadamente denunciadas y cuestionadas, si el interesado no tiene la certeza previa del procedimiento de revisión de la decisión judicial que ha afectado sus derechos. En este sentido, el control externo puede considerarse, al menos, fuertemente debilitado. En segundo lugar, la idea de diferenciar entre las hipótesis contenidas en el artículo 225 CPP. nos parece un tema delicado, que debiese abordarse evitando abrir espacios de interpretación que terminen por vaciar de contenido su función de control. Para estos efectos, y sólo con el objeto de aportar antecedentes para el futuro esclarecimiento de estos extremos, nos parece oportuno tener a la vista la involución que ha experimentado el debate jurisprudencial italiano. Tal como da cuenta la historia legislativa, el Código italiano fue parte de las fuentes que se tuvieron en cuenta para la estructuración de la reforma procesal penal chilena. Si bien no existe constancia alguna en orden a que el artículo 225 CPP. haya sido redactado en base a la regulación italiana, su lectura en paralelo es idéntica a la prevista en el numeral $1^{\circ}$ del artículo 271

\footnotetext{
${ }^{56}$ Horvitz, María Inés - López, Julián, cit. (n. 17), I, p. 532.
} 
del Código italiano ${ }^{57}$, titulado: "Prohibiciones de utilizaciones" y reza: "Los resultados de las interceptaciones no pueden ser utilizados en los casos que los mismos sean obtenidos fuera de los casos permitidos por las leyes o en los casos en que se hayan observado las disposiciones previstas en los artíiculos 267 y 268 inciso $1^{\circ}$ y $3^{\circ}$. El artículo 267 trata los presupuestos y formas del procedimiento de las interceptaciones. Esta disposición trata el deber de motivación y el estándar de los antecedentes en que debe basarse. Sólo efectuar esta conexión nos permite comprender las anotaciones vertidas por Horvitz y López ${ }^{58}$. Sin embargo, el instituto de la "inutilizzabilità" italiana es una figura que no tiene parangón con la regulación procesal penal chilena, por lo que su regulación no podría extrapolarse lisa y llanamente.

Retomando la cuestión de las hipótesis contenidas en el artículo 225 CPP., debe tenerse presente los inconvenientes que tal distinción ha significado en el contexto del artículo 271 del Código italiano. En efecto, en Italia, "de conformidad con el artículo 125 inciso $3^{\circ}$, los decretos judiciales deben ser motivados, bajo pena de nulidad, en los casos en que la motivación esté expresamente prescrita por la ley: es el caso del artículo 267, el cual exige que el decreto con el cual el ministerio público dispone las interceptaciones sea motivado" 59 . Sin embargo, el Código del 80, estableció en su artículo 271 la sanción de inutilizabilidad para el evento de incumplimiento de la obligación de motivación, como disposición específica en materia de interceptación telefónica. Mientras que en un primer momento se entendió claramente que la falta o insuficiencia de la motivación del decreto por parte del juez determinaba la inutilizabilidad de los resultados conseguidos a través de tales interceptaciones $^{60-61}$; con posterioridad ha surgido la tendencia de diferenciar

${ }^{57}$ Artículo 271: "Divieti di utilizzazione. 1. I risultati delle intercettazioni non possono essere utilizzati qualora le stesse siano eseguite fuori dei casi consentiti dalla legge o qualora non siano state osservate le disposizioni previste dagli artt. 267 e 268 commi 1 e 3".

${ }^{58}$ Véase nota $\mathrm{n} .57$.

${ }^{59}$ Maioli, Cesar - Cugnasco, Roberto, Profili normativi e tecnici delle intercettazioni dai sistemi analogici al voice over IP (Bologna, Gedit, 2008), p. 34. La traducción es nuestra.

${ }^{60}$ Di Martino, Corrad - Procaccianti, Teresa, Le intercettazioni telefoniche (Padova, Cedam, 2001), p. 109. "La mancanza o l'insufficienza della motivazione del decreto del giudice per le indagini preliminari determina l'inutilizzabilità dei risultati conseguiti tramite le intercettazioni [...], dovvendosi il precetto dell'artículo 271 c.p.p., dettato specificamente per le operazioni intercettive, considerare prevalente rispetto alla disposizione generale dell'artículo 125 c.p.p., che conmina la nullità qualora nei decreti manchi o sia viziata la motivazione imposta dalla legge".

${ }^{61}$ En efecto, esta es la posición que correctamente expresan los manuales. Véase, a modo ejemplar, PISAni, Mario (director), Manuale di procedura penale ( $8^{\mathrm{a}}$ edición, Bologna, Monduzzi, 2008), capítulo $17^{\circ}$ [de Oreste Diminioni], pp. 278 s. 
ambas hipótesis con el objeto de reducir el ámbito de operatividad de la inutilizabilidad (por lo demás más grave) sólo a la ausencia material de decreto de autorización. En otras palabras, la ausencia (física) de motivación se considera una cuestión diversa de la defectuosidad de la misma, vicio este último que comprendería las hipótesis de argumentaciones meramente formales, incompletas, insuficientes e ilógicas de los elementos contenidos en ella. De ahí que hablemos de una involución en el desarrollo jurisprudencial italiano.

\section{Conocimiento (notificación) del interesado como presupuesto para el} ejercicio del control externo.

La fuerza de las cosas indica que el único control eficaz debe provenir directamente del sujeto afectado, o su representante. Sin embargo, el procedimiento para recabar la autorización judicial se lleva a efecto sin contradictorio, con un cuestionable sistema de registro ${ }^{62} \mathrm{y}$, en la gran mayoría de los casos, sin que el afectado por la medida tenga jamás conocimiento alguno de la intrusión. Todas estas circunstancias se fundan en el entendido que, la naturaleza de la medida solicitada, implica que su eficacia dependa del secretismo de su ejecución, con el objeto de que el factor sorpresa para el afectado permita obtener resultados exitosos. Pasemos a analizar estas circunstancias.

a) Notificación al afectado por la medida. Parece existir consenso, tanto a nivel legal como doctrinal -en el ámbito nacional y comparado-, en orden a que el afectado no puede intervenir en el procedimiento dirigido a conseguir la autorización judicial de interceptación telefónica. Existe mediano consenso en torno a que decretada la autorización, dicha resolución no puede ser comunicada al afectado, sino hasta la ejecución de la medida. Así, el artículo 224 CPP. señala que: "la medida de interceptación será notificada al afectado por la misma con posterioridad a su realización, en cuanto el objeto de la investigación lo permitiere, y en la medida que ello no pusiere en peligro la vida o la integridad corporal de terceras personas. En lo demás regirá lo previsto en el artículo 182”. El análisis de esta disposición, requiere distinguir según si las operaciones de escucha telefónica arrojan, o no, resultados positivos.

${ }^{62}$ A propósito de la Solicitud N ${ }^{\circ} 928$, Ley de Transparencia, cit. (n, 34), el ministerio público primeramente consideró que el tenor de la información requerida debiese ser canalizada a través del Poder Judicial. Sin embargo, el pleno de la Corte de Apelaciones de Valparaíso acordó hacer devolución de los antecedentes no sólo en "consideración a que el ministerio público es el órgano persecutor y encargado de solicitar las órdenes de interceptación telefónica a los tribunales de justicia" sino que, también, porque son ellos los que tienen la información solicitada. De lo que es posible deducir que el Poder Judicial carece de un sistema de registro y seguimiento de las solicitudes de interceptación telefónica. 
i) Si de la ejecución de la medida de interceptación se obtienen resultados positivos. En la práctica, la ejecución de la medida de interceptación telefónica se acompaña de un trabajo de seguimiento por parte de las policías ${ }^{63}$. De este modo, con la información que se recopila a través de las escuchas telefónicas, las policías esperan la concreción de una situación de flagrancia para la detención del afectado por la medida. Luego, una vez detenido el sujeto, se continúa según las reglas generales establecidas en el Código: v.gr., la policía cuenta con 24 horas para poner al sujeto a disposición del juez de garantía con el objeto de proceder al control de legalidad de su detención. Dicho control se realiza en audiencia citada al efecto, con la concurrencia de todos los intervinientes (fiscal, imputado y defensor). A continuación, el fiscal expondrá al juez de garantía los antecedentes que determinaron la situación de flagrancia que posibilitaron la detención del imputado. Entre tales antecedentes, se encontrarán precisamente las aludidas escuchas telefónicas. En este momento, el imputado tomará conocimiento de la existencia de la medida intrusiva decretada en su contra. Los antecedentes de la resolución judicial autorizante son sumariamente expuestos, indicándose el juez que la dictó y la fecha en que se otorgó. El contenido de la interceptación telefónica es expuesto a través de la lectura resumida y parcelada del fiscal. En este punto se advierten dos cuestiones problemáticas.

Por una parte, ésta constituye la primera instancia procesal en que es posible cuestionar los requisitos de procedencia de la resolución judicial autorizante de la medida de interceptación. Desde una perspectiva pedestre, el ejercicio del derecho de defensa debe sortear la revisión de una carpeta de investigación, por regla general, muy extensa. Detectar el cumplimiento de los requisitos de procedencia a partir de la solicitud inicial de autorización de interceptación telefónica puede resultar una tarea en extremo difícil debido a la inmensa cadena de sujetos, causas, autorizaciones y prórrogas que pueden estar contenidas en la carpeta fiscal. Ello, además, suponiendo que

${ }^{63}$ Lamentablemente, en la praxis no se formulan reparos en torno a este tipo de actividad policial en circunstancias que, a mi juicio, también forma parte de aquellas actuaciones que requieren autorización judicial previa para su ejecución. Maturana MiQuel, Cristiá - Montero López, Raúl, cit. (n. 20), pp. 614 s, a propósito del análisis del artículo 226 CPP., señalan que una tercera hipótesis imaginable "consistiría en un cierto grado de afectación de la intimidad, pero en las cuales la actividad del investigador no se concreta en esferas claramente privadas que queden sujetas al estatuto protector del artículo 226, como sería los casos de seguimiento y fotografía o filmación sistémico y más o menos prologado de una persona a la cual se investiga cuando entra o sale de su casa u oficina; los lugares a los cuales se dirige, las personas con que se encuentra, el establecimiento de su rutina diaria, sus horarios, etc. para construir un cuadro de su vida cotidiana, lo que queda sujeto al estatuto normal para las actividades que afectan las garantías en la investigación contempladas en el artículo $9^{\circ}$, las que requieren autorización judicial previa”. 
toda la información se encuentre efectivamente en la carpeta, y no existan, como sucede, autorizaciones de interceptación telefónica contenidas en causas respecto de las cuales el ministerio público haya dispuesto el secreto de la investigación. Por último, como tendremos ocasión de comentar en el apartado siguiente, el sistema de registro de la tramitación de la autorización de la intervención, es del todo insatisfactorio.

En segundo lugar, otro gran obstáculo, ahora de carácter sustancial, dice relación con el derecho a un juez imparcial ${ }^{64}$. Suele ocurrir, que el juez de garantía ante quien se pretende discutir la legalidad o legitimidad de la resolución judicial autorizante, es el mismo que la ha ordenado. Es una situación particularmente grave, si se considera que, sea que la infracción de derechos fundamentales se alegue por la vía de la nulidad procesal, o, sea que se discuta mediante la solicitud de declaración de ilegalidad de la detención ${ }^{65}$ : en ambos casos, no existe posibilidad de revisión ante tribunal superior. Además, ante la obtención de resultados positivos, los jueces tienden a considerar dicha circunstancia como suficiente para excluir todo debate en torno al análisis

${ }^{64}$ Sobre todo si se tiene presente el fenómeno de "forum shoping" en que el ministerio público incurre a la hora de decidir la sede competente para la tramitación de la solicitud de interceptación telefónica (aún más, dentro de un juzgado de garantía compuesto por varios jueces, el "forum shoping" va referido a la individualización del juez de turno). En Italia, la cuestión ha sido detectada por la doctrina. Así, MaIOLI, Cesar - Cugnasco, Roberto, cit. (n. 59), p. 36. "Per quanto riguarda l'eventuale incompetenza del giudice emanante il decreto di autorizzazione, la Corte di Cassazione ha affermato che questa non vizia la validità del provvedimento [Cass. Sez. V., 28. 10. 1997, “Caputo", CED, 209973"]. En este contexto hace sentido la tendencia de recabar del concepto de prueba inconstitucional una fuente de prohibición probatoria en atención a la violación de la imparcialidad del tribunal. Véase MARINelli, Claudio, Intercettazioni processuali e nuovi mezzi di ricerca della prova (Torino, Giappichelli, 2007), p. 148. "Non è mancato neppure chi ha voluto riconoscere la diretta applicabilità al nucleo essenciale delle garanzie della giurisdizione, ricostruendo la terzietà e l'imparzialità dell'organo giudicante quali requisiti di utilizzabilità della prova, da inferire dall'artículo 111 Cost. In tale prospettiva, la prova assunta da parte di un giudice privo dei predetti caractteri dovrebbe ritenersi incostituzionale sia per la violazione del precetto, sia per la riflessa incidenza su fondamentali diritti del cittadino che rappresentano l'oggetto di tutela del giusto processo. Il rapporto antonomico tra mezzo dimostrativo e previsioni costituzionali si risolverebbe con l'espunzione del primo dallo spazio processuale, conseguendone l'inammissibilità e, ove già asunto, l'inutilizzabilità degli esiti”. Corresponde a una cuestión de mucho interés pero que escapa al objeto del presente trabajo.

${ }^{65} \mathrm{El}$ artículo 132 bis CPP. no obstante su cuestionable constitucionalidad, sólo prevé la facultad de recurrir a favor del ministerio público, es decir, en caso que se haya decretado la ilegalidad de la detención por alguno de los delitos expresamente indicados por la norma. 
de la legalidad o legitimidad de la autorización concedid ${ }^{66}$, olvidando que "la prueba que, eventualmente, sea descubierta con posterioridad, no agrega ni quita nada sobre la bondad de la valoración original"67. En palabras de Camon, para esta jurisprudencia cuentan los resultados de la interceptación: "si son positivos, esta suerte de temible sanatoria precluye toda cuestión sobre la legitimidad y fundamento del decreto" 68 .

ii) Si de la ejecución de la medida de interceptación no se obtienen resultados positivos. "En el caso de que la medida de interceptación no haya dado resultado positivo alguno y no se encuentre el afectado por ella personado en la causa, ciertamente éste no llegará a tener conocimiento de que estuvo sometido a tal vigilancia y de que fue levantado el secreto de sus comunicaciones, pero con toda razón Jiménez Campo señala que la resolución que dispuso la interceptación habrá de serle comunicada al afectado 'al término de la intervención en el derecho, pues de esta notificación postrera depende la posibilidad misma para el afectado de alzarse, mediante los recursos oportunos, frente a las irregularidades en que se haya podido incurrir"'69.

Atendido que en nuestra legislación la medida de interceptación telefónica puede afectar a personas distintas del imputado, debiere exigirse también la notificación de la ejecución de la medida de interceptación a su respecto, sea que existan o no resultados positivos. Este es el verdadero ámbito de aplicación del artículo 224 CPP. y no obstante ello, ni la tramitación legislativa, ni la doctrina, ni la jurisprudencia reparan en la relevancia que el mismo juega para contar con un eficaz sistema de control de las intervenciones telefónicas en Chile.

La única discusión que se plantea a propósito de "terceros" que hayan sido objeto de interceptación telefónica, se ubica con ocasión de la exclusión de prueba ilícita, en el sentido de determinar si el imputado puede o no alegar la infracción de tales derechos fundamentales, ajenos, para excluir prueba en su favor. Ejemplo de ello es el Oficio $\mathrm{N}^{\circ} 60$ del ministerio público, relativo a la prueba pericial en el nuevo sistema procesal penal, donde se advierte que otro de los problemas que pueden presentarse en relación con ciertas garantías, son cuestiones de interpretación en los casos en que el titular sea

${ }^{66}$ Implícitamente en causa rol 135-2008, RUC 0700709859-0, Corte de Apelaciones de Antofagasta, considerando $4^{\circ}$.

${ }^{67}$ Camon, Alberto, Le intercettazioni nel processo penale (Milano, Giuffrè, 1996), p. 119. La traducción es nuestra.

${ }^{68}$ Ibíd., p. 119. La traducción es nuestra. El autor hace referencia a las sentencias de la Corte de Casación italiana correspondientes a las sesiones IV, de 20 de febrero de 1991, "Morabito", y I, de 23 de marzo de 1994, "Pulito". Cfr. con el ímpetu de la sentencia $\mathrm{N}^{\circ} 34$ de la Corte Constitucional italiana de fecha 6 de abril de 1973.

${ }^{69}$ LópeZ DE Quiroga, Jacobo, cit. (n. 1), p. 203. 
una persona distinta del imputado (por ejemplo, en el caso de la violación de morada o de interceptación de comunicaciones). El citado oficio señala que: "aqui se plantea el problema de saber quién es la persona legitimada para reclamar de la violación del derecho en cuestión, si el titular del mismo por la intromisión sufrida o el imputado, por el peligro de ser condenado a base de la prueba ilícitamente obtenida. Pero dado que el tercero no es parte en el juicio, la alegación de ilicitud de la prueba tendrá que canalizarse a través del defensor en el marco de la defensa del imputado, pudiendo originarse problemas cuando no haya una coincidencia entre los intereses del imputado y del titular del derecho lesionado"70. Es decir, la infracción de derechos fundamentales de un tercero sólo se analiza desde el punto de vista de sus efectos en un proceso formalizado en contra de otro sujeto, y parece descartarse de plano la existencia de un pronunciamiento directo respecto de la afectación de derechos de dicho tercero.

Señalado lo anterior, es necesario denunciar que, en la práctica, el artículo 224 CPP. carece de toda aplicación. Existe tal displicencia que, doctrinariamente, la única referencia al modo en que debiere llevarse a efecto la notificación, expresa que: "por ser una actuación no jurisdiccional que corresponde a la etapa de la investigación a cargo del fiscal -al tenor de lo ordenado en el artículo 222 del precitado Código-, [...] la debe realizar éste bajo su responsabilidad, por cualquier medio razonable que resultare eficaz, siendo de su cargo acreditar la circunstancia de haberse realmente

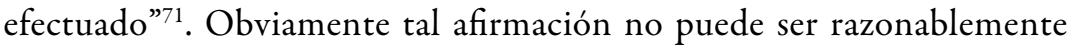
compartida, menos aun tratándose de una etapa desformalizada de investigación donde se ha verificado tan intensa interferencia en los derechos fundamentales de un ciudadano.

Esta despreocupación por el imputado respecto de quien no hay resultados, y por el tercero afectado en general, se debe en gran parte a que en Chile, luego de la intervención del juez de garantía para efectos de recabar la autorización o su prórroga, no hay control judicial sobre el desarrollo de la ejecución de la medida. Es decir, si el ministerio público no solicita la audiencia de control de detención, de formalización de investigación o no comunica su decisión de no perseverar, el juez se mantiene absolutamente ignorante de cuanto sucede con el resultado de las interceptaciones, con el tratamiento de las grabaciones, su archivo o destrucción. Por lo demás tal seguimiento es inconcebible, e incluso inexigible, si se considera el precario sistema de registro con que cuentan los juez de garantía a estos efectos. Del

${ }^{70}$ Ministerio Público, Fiscalía Nacional, Reforma procesal penal, Oficios del Fiscal Nacional. Materias procesales penales, 2001-2004 (Santiago, Editorial Jurídica de Chile, 2004), 438 p. Oficio $\mathrm{N}^{\circ}$ 60, de 31 enero de 2002, p. 311. El destacado es nuestro.

${ }^{71}$ NúÑEZ VÁsQueZ, Juan Cristóbal, cit. (n. 20), p. 92. 
mismo modo, si no tienen lugar algunas de las cuestiones anotadas, el sujeto afectado no tendrá jamás conocimiento de la intrusión.

Así las cosas, el afectado por una interceptación telefónica que no produzca resultados positivos, sólo tiene la remota posibilidad de conocer de tal intromisión en los casos en que el ministerio público haga aplicación de lo dispuesto en el artículo 248 letra c) c.p.p., esto es, comunique su decisión de no perseverar en el procedimiento, por no haberse reunido durante la investigación los antecedentes suficientes para fundar acusación. Decimos "remota", porque el mayor número de interceptación telefónica debiese tener lugar en materia de tráfico de drogas, donde, precisamente, el inciso final del artículo 24 Ley $\mathrm{N}^{\circ} 20.000$, permite, no obstante la intervención del juez de garantía, que en caso que las diligencias no dieren resultado, puedan de todos modos ser archivadas provisionalmente hasta que aparezcan mejores y nuevos antecedentes. En la discusión parlamentaria se "sostuvo que, si en la práctica estas medidas intrusivas no tienen resultado, para cerrar esa investigación el fiscal debe optar por el sistema de no perseverar en el procedimiento, lo que implica que algunos juzgados de garantía citen al afectado a una audiencia para comunicarle la decisión del fiscal, con los cual se enteran de que fueron objeto de una investigación y de las técnicas utilizadas"72. Es decir, el principio inspirador de la norma es precisamente dejar al afectado por la intrusión siempre ignorante de su ejecución, y por tanto, ajeno a toda posibilidad de control.

Este último argumento, es bastante similar al expuesto por el Tribunal Europeo de Derechos Humanos en sentencia de 6 de septiembre de 1978, sobre el caso "Klass contra Alemania", en materia de terrorismo, donde indicó que la notificación ulterior a cada individuo afectado por una medida posteriormente levantada podría comprometer el fin a largo plazo que motiva el origen de la vigilancia. A juicio del Tribunal Europeo: "esta notificación correría el riesgo de contribuir a revelar los métodos de trabajo de los servicios informativos, sus campos de observación e, incluso, la identidad de sus agentes". López de Quiroga, a cuya opinión adherimos, realiza una dura crítica a este argumento: señala que el artículo 8 de la Convención europea de derechos humanos puede ser interpretado en modo incompatible con lo dispuesto en el artículo 13 del mismo $^{73}$, que consagra el derecho a recurso efectivo. En consecuencia, si el artículo 13 impone un recurso efectivo interno, esto quiere decir que debe existir una notificación posterior, al menos de

${ }^{72}$ Historia de la Ley $N^{\circ} 20.000$, cit. (n. 18), p. 597 s.

${ }^{73}$ Artículo 13. "Derecho a un recurso efectivo". Toda persona cuyos derechos y libertades reconocidos en el presente Convenio hayan sido violados tiene derecho a la concesión de un recurso efectivo ante una instancia nacional, incluso cuando la violación haya sido cometida por personas que actúen en el ejercicio de sus funciones oficiales. 
la medida de interceptación adoptada, a fin de que el afectado pueda en su caso interponer el correspondiente recurso. Negar la notificación durante la medida, en razón de la inefectividad de ésta, puede ser comprensible, pero negar la notificación posterior -anulando así el recurso del artículo 13- es en todo caso inadmisible y basada en aprehensiones que no tienen asidero real ${ }^{74}$.

La citada convención, aunque más sucintamente, también se refiere al contenido previsto en los artículos 8 y 13 de la misma en sus homólogos artículos 11 y 8, respectivamente. En efecto, si el artículo 11 sobre "Protección de la honra y de la dignidad" señala que: "Nadiepuede ser objeto de injerencias arbitrarias o abusivas en su vida privada, en la de su familia, en su domicilioo en su correspondencia, ni de ataques ilegales a su honra o reputación $\left(\mathrm{N}^{\circ} 2\right)$; y que "Toda persona tiene derecho a la protección de la ley contra esas injerencias o esos ataques", debemos entender que la notificación ordenada en el artículo 224 debe practicarse indefectiblemente, para que pueda tener aplicación lo dispuesto en el artículo $8 \mathrm{~N}^{\circ} 2$ letra h) relativo al derecho de recurrir del fallo ante juez o tribunal superior, que en nuestro sistema procesal penal, podría concretarse únicamente a través del respectivo recurso de queja.

El derecho a la revisión judicial de la medida intrusiva autorizada, también debe enlazarse con la situación de aquel tercero que resulta imputado por un delito gracias a la información obtenida de la interceptación telefónica decretadas en un procedimiento diverso. En efecto, el artículo 223 inciso final CPP., señala que: "lo prescrito en el inciso precedente (relativo a la devolución y destrucción de las grabaciones que fueren irrelevantes) no regirá respecto de aquellas grabaciones que contuvieren informaciones relevantes para otros procedimientos seguidos por hechos que pudieren constituir un delito que merezca pena de crimen, de las cuales se podrá hacer uso conforme a las normas precedentes".

En este sentido, la Corte de Apelaciones de Antofagasta, en causa rol $\mathrm{N}^{\circ}$ 135-2008, rechaza el recurso de nulidad interpuesto por la defensa basado en el motivo absoluto del artículo 374 letras c) y e) CPP. en relación con los artículos 342 letra c) y 297 CPP., con un cuestionable argumento. La defensa denuncia haber tenido conocimiento de la existencia de interceptación telefónica sólo al inicio del juicio oral, a propósito de la declaración del policía testigo del procedimiento de detención en flagrancia del imputado, quien habría referido la existencia de una interceptación telefónica de una tercera persona como el antecedente que les habría permitido descubrir el hecho investigado en este juicio. En base a ello, se reclama no haber podido contar con los medios de defensa suficientes para poder contrarrestar esta prueba ni controlar la legalidad de la misma en cuanto al cumplimiento de

\footnotetext{
${ }^{74}$ López de Quiroga, Jacobo, cit. (n. 2), pp. 48 s.
} 
sus requisitos procesales. A juicio de la Corte: "tratándose de una medida intrusiva en otro proceso y que fue debidamente controlada por el juez de garantía, ningún perjuicio ha podido causar a la defensa técnica del imputado en los términos planteados, ya que no se mencionaron circunstancias de becho que pudieran explicar la indefensión que alega el recurrente. Con relación al control de legalidad propiamente tal, ninguna fiscalización podia hacer frente a una información recibida involuntariamente en otro proceso [...]", reiterando que: "ninguna duda razonable puede surgir sobre la interceptación telefónica en el marco de una investigación referida en otra causa". El razonamiento anotado, a nuestro juicio es errado, carente de análisis sistemático, y acentúa - una vez más- la necesidad de ahondar en las formas procesales que permitan contar con un efectivo control de las operaciones de interceptación ${ }^{75}$.

b) Notificación al afectado y secreto de la investigación. El artículo 224 CPP. señala expresamente que "en lo demás regirá lo previsto en el artículo 182", que regula el secreto de las actuaciones de investigación. Por una parte, dispone el secreto para los terceros ajenos al procedimiento y, por otra, -tratándose del imputado y demás intervinientes-, permite su procedencia en los casos en que el ministerio público lo considerare necesario para la eficacia de la investigación. Resulta relevante destacar dos aspectos: $i$ ) tal secreto sólo puede mantenerse por un plazo máximo de 40 días, siempre que el ministerio público identifique las piezas o actuaciones que van a ser objeto del mismo, existiendo el derecho de los intervinientes a solicitar su limitación o término; y ii) dicho secreto es improcedente tratándose de informes evacuados por peritos o de actuaciones en las que ha participado el tribunal o el propio imputado (entre otras). En la hipótesis que venimos analizando ha existido intervención judicial y recae precisamente sobre una actuación del imputado, por ende, en principio, no debería haber sido objeto de secreto. Sin embargo, atendida la naturaleza de la medida de interceptación, ella requiere de secreto para su eficacia y por ello se hace excepción a la regla del artículo $182^{76}$.

${ }^{75}$ CA de Antofagasta, Rol N 135-2008, RUC Nº700709859-0, Considerando $4^{\circ}$ y $5^{\circ}$. El espaciado es nuestro. Este criterio es destacado por la Unidad especializada de tráfico ilícito de drogas y sustancias estupefacientes en Figueroa Aste, Renzo, Criterios contenidos en las sentencias dictadas por infracción a la Ley $N^{\circ} 20.000$ entre los meses de agosto a octubre de 2008, en Revista Jurídica del Ministerio Público, 36 (octubre 2008), p. 107. En apoyo de esta posición se muestra Zavidich Diomedi, Carolina, Restricción a las comunicaciones telefónicas en la ley de drogas chilena, en Revista Jurídica del Ministerio Público, 44 (septiembre 2010), pp. 146- 161.

${ }^{76} \mathrm{~A}$ nuestro juicio el secreto en la solicitud de la medida a través de la intervención unilateral del MP, sin ser contradictorio, no es el único ni el más idóneo modo de proceder. Con todo, para efectos de esta exposición, trabajamos sobre la base de que dicho 
Ahora bien, una vez ejecutada la medida, el artículo 224 vuelve a plantear un estado excepcional al permitir el mantenimiento del secreto, no sólo cuando el objeto de la investigación exija mantenerlo, sino que además y copulativamente, requiriendo acreditar que la notificación pone en peligro la vida o integridad corporal de terceras personas. Esto significa que la mantención del secreto una vez ejecutada la medida, debe ser solicitada por el ministerio público al juez de garantía con el objeto de informarle la ausencia de resultados positivos y los antecedentes concretos por los cuales considera que la medida de interceptación no deba ser notificada. Estos antecedentes concretos deben referirse tanto a las exigencias precisas de la investigación que desarrolla, como a la circunstancia de existir peligro para la vida e integridad física de terceros debidamente determinados. Obtenida la autorización judicial, cobra plena aplicación la referencia expresa que el artículo 224 efectúa al artículo 182 CPP., esto es, el plazo máximo para mantener el secreto una vez ejecutada la interceptación, no puede ser superior a 40 días ${ }^{77}$.

Si bien el Código no regula el rol de control que el juez de garantía debiese desplegar durante la ejecución de la interceptación telefónica, la norma en comento parece suponer al menos una intervención posterior, precisamente a fin de dar cumplimiento con la notificación del sujeto afectado. El propio ministerio público ha señalado, a propósito de la reserva como medida de protección, que el fiscal debe oponerse "a la notificación al afectado de la medida de interceptación de comunicaciones telefónicas cuando ello pusiere en peligro la vida o la integridad corporal del testigo, en conformidad al artículo 224 CPP." 78 . Tal oposición sólo podría ser entendida en el marco del control que debe ejercer el juez de garantía a estos efectos, toda vez que no se prevé la intervención de contradictor.

Resta entonces analizar la situación desde la perspectiva de los artículos 36 ss. de la Ley $\mathrm{N}^{\circ} 20.000$. El artículo 36 permite al ministerio público disponer el secreto cuando estime existir riesgo para la seguridad de todos quienes hayan cooperado eficazmente en el procedimiento. Su inciso $2^{\circ}$ somete dicho secreto al régimen jurídico establecido en el artículo 182 CPP. modificando

secreto sería necesario para garantizar el éxito de la operación, tal como se asume en la práctica.

${ }^{77}$ Debe considerarse que uno de los principios rectores del actuar del MP es precisamente la publicidad de sus actuaciones: "por regla general, dejan de ser secretas para las partes, los registros de las actuaciones de las investigaciones que lleven a cabo los fiscales en ejercicio de la persecución penal pública, salvo excepciones en que pueda solicitarse al juez de garantía la reserva de las actuaciones por un plazo determinado (artículo 182 CPP)". Cfr. Carocca Pérez, Alex, cit. (n. 20), p. 29.

${ }^{78}$ Ministerio Público, Fiscalía Nacional, Reforma procesal penal, Instrucciones generales $N^{\circ} 26$ a 50, noviembre 2000 - febrero 2001 (Santiago, Editorial Jurídica de Chile, 2001), p. 140. 
únicamente su plazo máximo de extensión, esto es: hasta el cierre de la investigación ${ }^{79}$. Luego, particularmente atingente a nuestra hipótesis se encuentra el secreto previsto en el artículo 38 de la Ley $\mathrm{N}^{\circ} 20.000$, establecido con el objeto de asegurar un mejor resultado de la investigación. Esta norma señala que: "Sin perjuicio de lo dispuesto en el artículo 36, la investigación de los delitos a que se refiere esta ley será siempre secreta para los terceros ajenos al procedimiento y también para los terceros afectados por una investigación preliminar del ministerio público. Respecto del imputado y de los demás intervinientes, la investigación será secreta cuando así lo disponga el ministerio público, por un plazo máximo de 120 dias, renovables sucesivamente, con autorización del juez de garantía, por plazos máximos de 60 dias". Su inciso $2^{\circ}$ agrega que: "A estas investigaciones no les será aplicable lo dispuesto en el artículo 186 CPP., cuando se haya decretado el secreto en los términos señalados en el inciso precedente". El estudio de esta norma amerita algunas distinciones.

En primer lugar, amplía el espectro de sujetos respecto de los cuales es procedente el secreto sin expresión de causa y sin intervención judicial, es decir, además de los terceros ajenos al procedimiento (= artículo 182 inciso $\left.1^{\circ} \mathrm{CPP}.\right)$, agrega a los terceros afectados por una investigación preliminar, quienes se mantendrían ajenos al conocimiento de tal intrusión. A su respecto, la expresión "investigación preliminar" debe entenderse restringida a la aplicación del secreto a la fase de investigación desformalizada. Por tanto, una vez formalizada la investigación en contra del imputado, los terceros afectados por la investigación preliminar debiesen ser necesariamente notificados en conformidad al artículo $224 \mathrm{CPP}$. Sin embargo, se mantiene la cuestión en el caso de terceros afectados por una investigación preliminar

${ }^{79}$ Guerra Fuenzalida, Manuel, El secreto de la investigación en los casos de la Ley 20.000, en Revista Jurídica del Ministerio Público, 40 (septiembre 2009), p. 73. En cuanto a la ratio de esta norma, Guerra Fuenzalida explica que ella "responde a la lógica de la especial complejidad que revisten las investigaciones por delitos de la Ley $\mathrm{N}^{\circ} 20.000$, en que la realidad indica que la posibilidad de que quienes detenten alguna de las calidades mencionadas en la disposición objeto de estudio están naturalmente expuestos a represalias que pueden llegar a afectar incluso su vida, por lo que puestos en juego por un lado la posibilidad de acceso a los intervinientes, frente a la necesidad de dotar de eficacia a las investigaciones relativas al tráfico de drogas, la ley ha optado por favorecer esta última, resguardando el derecho de la defensa a que en la oportunidad procesal relativa al Juicio Oral tendrá de todos modos la posibilidad de conocer todos los antecedentes y poder preparar su Teoría del Caso". A nuestro juicio, es oportuno especificar que tanto la finalidad de protección de la norma, como la referencia expresa al cierre de la investigación, suponen su aplicación a causas judicializadas, v.gr. causas en que el MP haya procedido a la formalización respectiva. Además es necesario advertir que no es efectivo que se tenga acceso a la totalidad de los antecedentes antes del juicio oral. 
dirigida en contra de un imputado respecto de quien no se ha formalizado investigación por no haberse obtenido resultados positivos de cargo. En este sentido, es del caso hacer presente que si bien la norma en comento no fue objeto de control de constitucionalidad en su tramitación legislativa, la misma infringe lo dispuesto en el artículo $19 \mathrm{~N}^{\circ} 3,4,5$, y 26 CPol. y de los artículos 8 y 11 de la Convención Americana de los Derechos del Hombre (de estos últimos en los términos que ya tuvimos ocasión de explicar).

En efecto, el artículo 1 C.Pol. concibe a la persona como fundamento de todos los derechos que le son inherentes y de las garantías necesarias para resguardarlos. El artículo $19 \mathrm{~N}^{\circ} 4^{\circ} \mathrm{C}$.Pol. asegura, sin distinción ni restricción alguna: "El respeto y protección a la vida privada y pública y a la honra de la persona y de su familia"; y el $\mathrm{N}^{\circ} 5^{\circ}$ agrega que se reconoce, igualmente: "La inviolabilidad del hogar y de toda forma de comunicación privada" puntualizando que "las comunicaciones y documentos privados" sólo pueden "interceptarse, abrirse o registrarse en los casos y formas determinados por la ley". De este modo, si bien el legislador se encuentra habilitado para regular su ejercicio, la propia Carta Fundamental le impide, al hacer uso de sus atribuciones, afectar el derecho en su esencia, imponerle condiciones, tributos o requisitos que impidan su libre ejercicio o privarlo de la tutela jurídica que le es debida. Es decir, en tal regulación, no le es permitido al legislador dictar normas que impliquen afectar el núcleo esencial del derecho asegurado o despojarlo de la protección que le corresponde. A mi juicio, el secreto absoluto de la medida de interceptación telefónica respecto de un tercero afectado infringe lo dispuesto en el artículo $19 \mathrm{~N}^{\circ} 26$ en cuanto afecta el derecho en su esencia al privarlo de la tutela jurídica que le es debida. En efecto, la intervención judicial en la autorización de la medida intrusiva, sin conocimiento del afectado, resulta absolutamente insuficiente si no se contemplan los controles heterónomos indispensables de carácter jurisdiccional para que los derechos del afectado sean debidamente respetados por el órgano investigador. Sobre todo tratándose de una hipótesis que hace excepción al principio de publicidad que rige la reforma procesal penal, como concreción de una de las garantías de un procedimiento y una investigación racionales y justos en los términos del artículo $19 \mathrm{~N}^{\circ} 3$ inciso $5^{\circ} \mathrm{CPol}{ }^{80}$.

En segundo lugar, respecto del imputado y demás intervinientes, se aumenta el plazo de extensión del secreto a 120 días, renovables sucesivamente con autorización judicial por plazos máximos de 60 días. A juicio de Guerra Fuenzalida, una interpretación sistemática de las normas permite sostener, en

\footnotetext{
${ }^{80}$ Este razonamiento reproduce en parte la línea argumentativa del Tribunal Constitucional en Oficio a la Cámara de origen según consta en la Cuenta en Sesión $\mathrm{N}^{\circ} 45$, Legislatura 352 de fecha 25 de enero de 2005, declaración de inconstitucionalidad del artículo 27 letra a) del proyecto. Historia de la Ley $N^{\circ} 20.000$, cit. (n. 18), p. 1285 ss.
} 
términos unívocos, la consagración de "una prerrogativa al ministerio público en orden a poder decretar el secreto total y absoluto de la investigación por un plazo de 120 días, sin que exista la posibilidad de discutir su levantamiento durante dicho período" ${ }^{\prime 1}$, constituyendo una excepción a la regulación del artículo $182 \mathrm{CPP}$. que "razona sobre la base de que durante el período de vigencia del mismo los intervinientes tienen el derecho a solicitar la revisión de la mantención del secreto" 82 . Así, para los casos en que transcurrido el plazo de 120 días el Fiscal opte por solicitar la renovación del secreto, ello debiese ser resuelto por el juez de garantía por períodos sucesivos no pudiendo exceder cada una el plazo de 60 días. Agrega que, "de otra forma no se entendería la expresión 'Sin perjuicio de lo dispuesto en el artículo 36' con que comienza la redacción del artículo 38 de la Ley $\mathrm{N}^{\circ} 20.000$, toda vez que [...] la norma del artículo 36 ya se refiere al secreto, con lo que el artículo 38 , si no tuviese el sentido que proponemos, sería tautológico, ya que repetiría la posibilidad de un secreto susceptible de revisión por parte del juez de garantía desde el primer momento" 83 .

Sin embargo, el citado autor no desarrolla y por ende no descarta una segunda interpretación posible, cual es: el artículo 36 dispone la facultad del ministerio público de "disponer" el secreto con fines de protección de determinadas personas, pero tal como hemos señalado, lo somete a la regulación del artículo182, salvo en cuanto a la extensión de la duración del secreto. Por tanto, el hecho de que el artículo 38 señale que "la investigación será secreta cuando así lo disponga el ministerio público" no difiere de la expresión semántica de que se vale el artículo 36, y en consecuencia no obsta a la aplicación del estatuto contenido en el artículo $182 \mathrm{CPP}$. aunque ampliando la extensión del plazo original de 40 a 120 días y estableciendo la posibilidad de prórrogas sucesivas que no se contemplan en el Código. Así, la utilización de la expresión "sin perjuicio" se debe precisamente al diverso objetivo con que se ha consagrado el secreto: como protección de determinadas personas en el artículo 36 y como medida para asegurar el mejor resultado de la investigación en el artículo 38, pero en ningún caso la prerrogativa que el autor parece advertir en favor del ministerio público.

En este contexto, la aplicación de lo dispuesto en el artículo $224 \mathrm{CPP}$. se mantiene incólume en una interpretación constitucionalmente orientada. El artículo 24 de la Ley $\mathrm{N}^{\circ} 20.000$ hace excepción únicamente respecto de los artículos 222 inciso $4^{\circ}$ y $167 \mathrm{CPP}$., remitiéndose en lo restante a la regulación establecida en el Código y por ende exige la aplicación del artículo 224.

\footnotetext{
${ }^{81}$ Guerra Fuenzalida, Manuel, cit. (n. 79), p. 76.

${ }^{82}$ Ibíd., p. 75.

${ }^{83}$ Ibíd., p. 77.
} 
El problema quedaría reducido a establecer cuál es el plazo máximo para la mantención del secreto de la medida de interceptación ya ejecutada: si es el plazo máximo de 40 días, no prorrogable del artículo 182 CPP., o el plazo de 120 días, prorrogable sin limitación temporal, por periodos de 60 días, del artículo 38 de la Ley $\mathrm{N}^{\circ} 20.000$.

Me parece que la respuesta ha de ser forzosamente la primera. La Ley $\mathrm{N}^{\circ} 20.000$, dictada con posterioridad a la entrada en vigencia del Código, contiene una serie de normas que regulan los casos en que se puede decretar el secreto de la investigación otorgando al ente persecutor un margen mayor para $\mathrm{l}$ i $\mathrm{m}$ it a r la publicidad, frente a la norma general del artículo 182 CPP. ${ }^{84}$, pero no para a b o l i $\mathrm{l}$ a . De hecho, bajo ambas disposiciones (artículo 182 CPP. y artículo 38 de la Ley $\mathrm{N}^{\circ} 20.000$ ) subyace el supuesto de que la investigación se encuentra formalizada o que la misma es conocida por el imputado o afectado, de ahí que pueda comprenderse la facultad de intervenir solicitando el término o reducción del secreto; sin embargo tratándose de la hipótesis que venimos trabajando, la indefensión del sujeto es aún más fuerte, razón por la cual debe optarse por aquella solución que asegure su efectiva tutela, cuestión que no es garantizada por una norma que admite un secreto indefinido sobre la base de prórrogas sucesivas.

Respecto de los terceros, el problema pasa por dejar en claro que la intromisión en el derecho fundamental de la inviolabilidad de las comunicaciones no se agota única y exclusivamente desde la perspectiva de su control para los efectos de la defensa técnica respecto de la eventual imputación de cargos. Se trata de un derecho que por su carácter debe gozar de tutela jurisdiccional y de defensa, por decirlo de algún modo, "independiente". En cambio, tratándose de los imputados respecto de quienes no se han obtenidos resultados positivos, la cuestión exige determinar desde cuándo se reconocerán los derechos y garantías asociados a dicha calidad. El artículo 7 titulado "Calidad de imputado", prescribe que: "Las facultades, derechosy garantías que la C.Pol. de la República, este Código y otras leyes reconocen al imputado, podrán hacerse valer por la persona a quien se atribuyere participación en un hecho punible desde la primera actuación del procedimiento dirigido en su contra y hasta la completa ejecución de la sentencia". A continuación, su inciso $2^{\circ}$ precisa el momento, al detallar que: "Para este efecto, se entenderá porprimera actuación del procedimiento cualquiera diligencia o gestión, sea de investigación, de carácter cautelar o de otra especie, que se realizare por o ante un tribunal con competencia en lo criminal, el ministerio público o la policía, en la que se atribuyere a una persona responsabilidad en un hecho punible"ss.

\footnotetext{
${ }^{84}$ Ibíd., p. 72.

${ }^{85}$ En esta dirección se encuentran también el artículo 8 inciso $1^{\circ} \mathrm{CPP}$. al señalar
} 
Si bien parece existir consenso en que la esencia del derecho a la defensa está dada por la necesidad de que el imputado cuente con asistencia letrada desde los primeros actos del procedimiento dirigidos en su contra, a mi juicio ello no puede traducirse únicamente en el momento en que se formaliza la investigación en su contra o se discute la legalidad de su detención ${ }^{86}$. El artículo 102 inciso $1^{\circ}$ CPP., parte final, da cuenta de ello, por lo que una interpretación contraria y una exclusión permanente del conocimiento de la medida intrusiva, han de ser necesariamente entendidos como una negación del derecho de defensa.

Con todo, inversamente a cuanto se ha expuesto, la notificación al afectado y al imputado en contra quien no se han obtenido resultados positivos de cargo, por sí sola, en forma independiente, es lisa y llanamente omitida, sin que el juez de garantía ejerza control alguno, y sin que exista acreditación ni valoración de ninguna especie.

c) Unilateralidad de la solicitud de autorización de intervención telefónica. El Código Procesal Penal no contiene disposiciones que detallen el modo en que la solicitud debe ser formulada. No indica si la misma debe plantearse en audiencia o simplemente por escrito. Carocca Pérez refiriéndose a la autorización judicial previa de actuaciones que perturben o restrinjan derechos asegurados por la Constitución y en correlación con lo dispuesto en los artículos $80 \mathrm{~A}$ inciso $3^{\circ}$ de la Ley Orgánica constitucional del ministerio público, y 9, 70 y 236 CPP.. señala que: “[...] la aprobación de tales medidas debe hacerse de acuerdo a la regla conforme a la cual adoptan sus decisiones tales juzgados de garantía, que es como producto de una audiencia, que debe desarrollarse con asistencia de todas las partes, salvo excepciones en que se autoriza a desarrollarla sin asistencia del imputado o de su defensor, porque se estima necesario llevar a efecto tales diligencias de investigación sin previa comunicación al afectado" 87 .

En posición diametralmente opuesta se encuentra el ex fiscal nacional don Guillermo Piedrabuena, para quien la solicitud de los fiscales a los juzgados de garantía durante la investigación no siempre debía dar lugar a una audiencia, en especial tratándose de diligencias urgentes y de aquellas propuestas en el marco de una investigación preliminar en que no se había formalizado la investigación, ya que ello originaría una excesiva demora en la resolución

que: "el imputado tendrá derecho a ser defendido por un letrado desde la primera actuación del procedimiento dirigido en su contra”; y el artículo 93 letra b) CPP. al disponer que: "Todo imputado podrá hacer valer, hasta la terminación del proceso, los derechos y garantias que le confieren las leyes. En especial, tendrá derecho a: b) Ser asistido por un abogado desde los actos iniciales de la investigación".

${ }^{86}$ Cfr. Guerra Fuenzalida, Manuel, cit. (n. 79), p. 77.

${ }^{87}$ Carocca Pérez, Alex, cit. (n. 20), p. 29. 
de materias y diligencias que por su propia naturaleza requieren de rapidez para ser eficaz. A su juicio, tales audiencias públicas tampoco se justifican cuando durante la investigación no había imputados u otros intervinientes a quien escuchar. En este sentido, afirmaba que “(...) la Fiscalía ha estimado que salvo que la ley expresamente ordene celebrar una audiencia con citación de los intervinientes, los jueces deberían resolver de la manera más directa e informal posible si dan o no lugar a las peticiones del fiscal, sin perjuicio de los reclamos o recursos de los intervinientes" ${ }^{88}$. El citado autor entendió encontrar respaldo a su posición a partir de la Ley $\mathrm{N}^{\circ} 19.789$ que introdujo modificaciones al Código Procesal Penal; entre ellas añadió un nuevo inciso final al artículo 9 CPP. del siguiente tenor: "Tratándose de casos urgentes, en que la inmediata autorización fuere indispensablepara el éxito de la diligencia, podrá ser solicitada y otorgada por cualquier medio idóneo al efecto, tales como teléfono, fax, correo electrónico u otro, sin perjuicio de la constancia posterior". Si bien señala que tal norma expresa no debió haber sido necesaria -porque la exigencia de la concurrencia personal del fiscal al tribunal no se encontraba establecida en el Código-, estima que la misma permite superar las dificultades planteadas por algunos juzgados de garantía que exigían la concurrencia personal y física del fiscal al Tribunal o la realización de una audiencia o la petición por escrito, permitiendo agilizar la obtención de esa autorización previa, en casos de diligencias urgentes. No obstante lo indicado, reconoce que "en cierta medida el problema subsiste porque deja entregado al juez de garantía el otorgamiento de una autorización judicial por cualquier medio idóneo en los casos urgentes, si bien el espíritu general de la nueva legislación es que las autorizaciones en dichos casos se soliciten y concedan por una vía rápida e informal, como el teléfono, el fax, el correo electrónico u otro medio idóneo, sin perjuicio de la constancia posterior" ${ }^{\prime 9}$.

En efecto, no obstante haberse tratado de un tema en cierta medida discutido en los albores de la reforma, -existiendo jueces que consideraban necesaria la celebración de una audiencia privada con el fiscal, pero sujeta a los sistemas de registro de audio comunes a toda audiencia- la práctica judicial

${ }^{88}$ Piedrabuena Richard, Guillermo, Exposición del Fiscal Nacional en la Universidad de Concepción sobre "Los ajustes a la Reforma Procesal Penal", 28 de septiembre de 2001, en Revista Jurídica del Ministerio Público, 5 (septiembre 2001), p. 63 s. En los mismos términos, Piedrabuena Richard, Guillermo, Exposición del Fiscal Nacional en la Universidad Mayor de Temuco sobre "Estado actual de la Reforma Procesal Penal", 20 de diciembre del 2001, en Revista Jurídica del Ministerio, 8 (diciembre 2001), pp. 108 s.

${ }^{89}$ PIEDRABUENA RiChARD, Guillermo, Informe y comentario acerca de las modifcaciones al Código Procesal Penal introducidas por la ley 19.789, contenidos en el Oficio Circular $N^{\circ} 053$ de fecha 29 de enero de 2002, en Revista Jurídica del Ministerio, 9 (marzo 2002), pp. 128 s. 
ha finalmente arribado a un cuestionable modo de proceder. Actualmente no existe reparo en torno a que la solicitud pueda ser formulada únicamente por escrito, o bien por escrito previa audiencia privada con el fiscal, personalmente o a través de otro medio idóneo ${ }^{90}$, exenta de las formalidades de las audiencias en general, esto es, en el despacho del juez o a través de otra forma idónea de comunicación. Con ello quedan atrás afirmaciones tales como la expresada por Chahuán Sarrás, en el sentido que la medida debía ser solicitada por el fiscal en audiencia unilateral con el juez de garantía, lo que a su juicio, resultaba de toda lógica, "si se tiene presente que, en la práctica de la actuación, los agentes del Estado actúan de forma encubierta, sin control por parte del público o los intervinientes y, por lo mismo, imposibilitando cualquier defensa del imputado" 1 .

Luego, fuera de los casos en que la solicitud se acompaña de audiencia privada, el procedimiento escrito implica que el juez tome su decisión en base a la descripción argumentada que en él se contenga, con los énfasis y selecciones que el propio solicitante estime conveniente realizar ya que "no existe obligación legal de acompañar copia de antecedentes concretos, ni mucho menos la totalidad de la carpeta investigativa. Por eso, en teoría es perfectamente posible que se autoricen interceptación telefónica sobre la base de fragmentos de declaraciones sacadas de contexto, cortadas y pegadas según una legítima pero unilateral estrategia del persecutor"92.

${ }^{90}$ En este contexto se puede comprender lo afirmado en el Manual sobre interceptación telefónica del ministerio público, que refiriéndose al procedimiento de ejecución de la medida por parte de la empresa Claro, señala: "Las conexiones, según informó la empresa, se realizan según orden de llegada del requerimiento. En casos de extrema urgencia, es menester que los Fiscales comuniquen esta situación al correo [...], in for $\mathrm{r}$ mando si se cuenta con alguna autorización verbal del juez de Garantía, para hacerla llegar posteriormente de manera formal; todo con el objeto de agilizar el trámite". Ministerio Público, Fiscalía Nacional, Unidad Especializada de Tráfico Ilícito de Drogas y Estupefacientes, Manual sobre Interceptaciones Telefónicas, p. 17. El expandido es nuestro.

${ }^{91}$ Chahuán SARrás, Sabas, cit. (n. 22), p. 206.

${ }^{92}$ Weezel van, Ale - Darricades, Tomás, cit. (n. 25) p. 41. Ejemplo prístino de esta situación es la sentencia de la $3^{a}$ sala constitucional de la Corte Suprema, rol $N^{\circ}$ 2765-2009, que acoge el recurso de casación en el fondo interpuesto contra la sentencia de la Corte de Apelaciones de Temuco que revocó la de primer grado que había acogido la demanda y condenado al Fisco a pagar la suma de $\$ 100.000 .000$ por concepto de daño moral, a favor del abogado Pablo Ortega Manosalva por haber sido objeto de interceptación telefónica ilegales por parte del ministerio público mientras ejercía la defensa de imputados en el marco del llamado conflicto mapuche. El considerando $7^{\circ}$ letra f) señala: "Que en la audiencia reservada solicitada por el ministerio público se pidió la medida intrusiva de interceptación telefónica del Sr. Ortega, sin manifestar a la jueza de garantía que éste detentaba la calidad profesional de abogado, que asesoraba juridi- 
Se trata de un aspecto que a nuestro juicio se agrava aún más tratándose de solicitudes que se tramitan por teléfono, pretendiendo aplicar la referencia a medios idóneos del inciso final del artículo $9^{\circ}$ c.p.p. Por una parte, en la praxis no puede estimarse que el debate de una cuestión de esta naturaleza pueda efectuarse satisfactoriamente a través de este medio, el cual por ello no sería idóneo; y por otra, en la hipótesis en que se estime idóneo (cosa que no compartimos) la configuración de un caso de urgencia tampoco es acreditado por el ministerio público ni mucho menos fundamentado por el tribunal en su orden verbal. "El mayor riesgo, es que la autorización oral termine por perder todo carácter de excepcionalidad, transformándose en un modo normal de proceder, sobre todo si se tiene presente que se trataría de un proceder menos laborioso: la interceptación puede de hecho ser decidida sin una cuidadosa verificación de los presupuestos de admisibilidad, mientras que la motivación posterior puede resultar más fácil sobre la base de operaciones ya ejecutadas" 93 . Por ende, atendidas las consideraciones críticas de fondo que se han esbozado, esta posibilidad debiese ser ciertamente descartada.

\section{CONCLUSIONES}

$1^{\circ} \mathrm{El}$ sistema de control interno de las intervenciones telefónicas en Chile carece de desarrollo legal, doctrinal y jurisprudencial, por lo que en la práctica es casi inexistente. Sólo como punto de partida, urge determinar el contenido de los requisitos legales de procedencia claves, esto es, la inteligencia de aquello que debe constituir "fundadas sospechas" y ser "imprescindible", con el objeto de proveer al juez de criterios concretos, en línea con estándares de convicción que le sean conocidos y por ello fácilmente aprehensibles. Devolver el carácter excepcional de la aplicación de la medida y recordar la afectación de derechos que conlleva su laxa concesión, son ideas que deben reforzarse en la formación judicial.

$2^{\circ}$ El panorama desalentador en torno a la motivación de la sola proceden-

camente a algunos de los imputados en la causa y que tenía la representación judicial de algunos de ellos en otras causas, hechos conocidos por el ministerio público (considerando $26^{\circ}$ de la sentencia de primera instancia, reproducido por del segunda)". Especificando en el considerando 140: "Que al concluir los jueces de segunda instancia que no se verificaban los supuestos para lograr que la pretensión indemnizatoria del actor fuera acogida, pues los fiscales involucrados actuaron conducidos desde su personal perspectiva, desatendieron los lineamientos normativos antes descritos cuya infracción se ha denunciado, lo que importa transgresión al precepto".

${ }^{93}$ Illuminati, Giulio, La disciplina processuale delle intercettazioni, cit. (n. 24), p. 101, a propósito de las serias dudas de inconstitucionalidad suscitada por las autorizaciones verbales introducidas por el Decreto Ley $\mathrm{N}^{\circ}$ 59/1978 al artículo 226-ter CPP. La traducción es nuestra. 
cia de la medida, hace imposible siquiera pronunciarse sobre la motivación en la concesión de prórrogas. Si bien el remedio de lo primero debiese llevar de la mano la corrección de lo segundo, entendemos que los criterios restrictivos que deberán desarrollarse para la motivación de prórrogas deberán ser aún más exigentes para establecer el número de ellas. Esto, atendida la inadecuada fórmula al infinito con que las mismas han sido consagradas en la legislación chilena, en una etapa de investigación desformalizada donde el derecho al plazo razonable queda entredicho.

$3^{\circ}$ El efectivo ejercicio del derecho de defensa implica, ante todo, que el sujeto afectado por una medida de intervención y limitación de un derecho fundamental, tenga conocimiento de que ha sido objeto de la misma. Luego, el nudo conocimiento debe ser acompañado de un procedimiento que asegure su acceso tanto al contenido de la resolución judicial autorizante como a los antecedentes que se tuvieron a la vista para concederla. La posibilidad de ejercer un control externo por la vía de la revisión jurisdiccional, ciertamente repercutirá en la calidad de la fundamentación de la autorización de la medida y sus respectivas prórrogas. Luego, el sistema debe proveer una clara señalización de la instancia jurisdiccional de revisión y del medio procesal destinado a hacerlo valer, en modo que el régimen sancionatorio aplicable sea conocido con anterioridad por todos los intervinientes, especialmente por el afectado.

$4^{\circ}$ Por último, para que el juez pueda llevar a cabo racionalmente su cometido, es necesario no sólo replantear la for m a en que el mismo se impone de la solicitud fiscal, dotándolo de un adecuado sistema de registro, sino también suministrándole la totalidad de los antecedentes que inciden en su valoración.

\section{BIBLIOGRAFÍA}

Camon, Alberto, Le intercettazioni nel processo penale (Milano, Giuffrè, 1996).

Carocca Pérez, Alex, Manual el nuevo sistema procesal penal (3 $3^{a}$ edición, Santiago, LexisNexis, 2005).

Cerda San Martín, Rodrigo - Hermosilla Iriarte, Francisco, El código procesal penal. Comentarios, concordancias, jurisprudencia ( $2^{\text {a }}$ edición, Santiago, Librotecnia, 2006).

Cerda San Martín, Rodrigo, Manual del nuevo sistema de justicia criminal (Santiago, Librotecnia, 2005).

Chahuán SARrás, Sabas, Manual del nuevo procedimiento penal ( $2^{a}$ edición, Santiago, LexisNexis, 2002).

Correa Selamé, Jorge, Curso de derecho procesal penal (Santiago, Ediciones Jurídicas de Santiago, 2003). 
Di Martino, Corrad - Procaccianti, Teresa, Le intercettazioni telefoniche (Padova, Cedam, 2001).

Duce, Mauricio - Riego, Cristián, Introducción al nuevo sistema procesal penal (Santiago, Ediciones Universidad Diego Portales, 2002), I.

Dugue González, Catalina, El agente encubierto y la interceptación o grabación de telecomunicaciones en las investigaciones de delitos sexuales, en Revista Jurídica del Ministerio Público 46 (marzo de3 2011).

Figueroa Aste, Renzo, Criterios contenidos en las sentencias dictadas por infracción a la Ley $N^{\circ} 20.000$ entre los meses de agosto a octubre de 2008, en Revista Jurídica del Ministerio Público 36 (octubre de 2008).

Gálvez Blanco, Ricardo, Intervención de teléfonos en la legislación chilena, en Revista Chilena de Derecho, 19 (Pontificia Universidad Católica de Chile, 1992) 3.

Grevi, Vittorio, Appunti in tema di intercettazioni telefoniche operate dalla polizia giudiziaria, en Rivista Italiana di Diritto e Procedura Penale, 10 (1967) 2.

Grevi, Vittorio, Insegnamenti, moniti e silenzi della Corte Costituzionale in tema di intercettazioni telefoniche, en Giurisprudenza costituzionale (1973).

Grevi, Vittorio, Intercettazioni telefoniche e principi costituzionali, en Rivista Italiana di Diritto e Procedura Penale (1971).

Guerra Fuenzalida, Manuel, Elsecreto de la investigación en los casos de la Ley 20.000, en Revista Jurídica del Ministerio Público, 40 (septiembre 2009).

Hermosilla Arriagada, Germán, Nuevo procedimiento penal (2ª edición, Ediciones Universidad Central, Santiago, Chile, 2005), II.

Historia de la Ley $\mathrm{N}^{\circ}$ 18.314: Determina conductas terroristas y fija su penalidad, disponible en http://www.leychile.cl/Consulta/portada_hl?tipo_norma=XX1\&nro_ ley $=18314 \&$ anio $=2014$

Historia de la Ley $\mathrm{N}^{\circ} 19.366$ Sanciona el tráfico ilícito de drogas y sustancias estupefacientes, dicta y modifica diversas disposiciones legales y deroga Ley $N^{\circ} 18.403$, DO. 30.1.1995, 960 p., disponible en: http://www.leychile.cl/Consulta/portada_hl?tipo_norma $=X X 1 \&$ nro_ley $=193668$ anio $=1995$

Historia de la Ley N 19.696 Establece Código Procesal Penal, DO. 12.10.2000, 2479 p., disponible en: http://www.leychile.cl/Consulta/portada_hl?tipo_ norma $=X X 1 \&$ nro_ley $=19.696 \&$ anio $=2014$

Historia de la Ley $\mathrm{N}^{\circ} 19.927$ Modifica el Código penal, el Código de Procedimiento Penal y el Código Procesal Penal en materia de delitos de pornografía infantil, DO. 14.1.2004, 560 p., disponible en: http://www.leychile.cl/Consulta/portada_hl?tipo_norma $=X X 1 \&$ nro_ley $=19.927 \&$ anio $=2014$

Historia de la Ley $\mathrm{N}^{\circ} 20.000$ Sustituye la Ley $N^{\circ} 19.366$, que sanciona el tráfico ilicito de estupefacientes y sustancias sicotrópicas, DO. 16.2.2005, 1379 p., disponible en: http://www.leychile.cl/Consulta/portada_hl?tipo_norma=XX1\&nro_ ley $=20000 \&$ anio $=2014$

Horvitz, María Inés - López, Julián, Derecho procesalpenal chileno (Santiago, Editorial jurídica de Chile, 2002), I.

Illuminati, Giulio, La disciplina processuale delle intercettazioni (Milano, Giuffrè, 1983).

LÓPEZ DE Quiroga, Jacobo, Las escuchas telefónicas y la prueba ilegalmente obtenida (Madrid, Akal, 1989).

Maioli, Cesare - Cugnasco, Roberto, Profili normativi e tecnici delle intercettazioni dai sistemi analogici al voice over IP (Bologna, Gedit, 2008)p. 
MARINelli, Claudio, Intercettazioni processuali e nuovi mezzi di ricerca della prova (Torino, Giappichelli, 2007).

Maturana Miluel, Cristián - Montero López, Raúl, Derecho procesal penal (Santiago, Editorial Abeledo Perrot, 2012), II.

Medina Jara, Rodrigo - Morales Palacios, Luis - Dorn Garrido, Carlos, $M a$ nual de derecho procesal penal (Santiago, LexisNexis, 2005)p.

Ministerio Público, Fiscalía Nacional, Reforma procesal penal, Instrucciones generales $N^{\circ}$ 26 a 50, noviembre 2000 -febrero 2001 (Santiago, Editorial Jurídica de Chile, 2001).

Ministerio Público, Fiscalía Nacional, Reforma procesal penal, Oficios del Fiscal Nacional. Materias procesales penales, 2001-2004(Santiago, Editorial Jurídica de Chile, 2004).

Ministerio Público, Fiscalía Nacional, Reforma procesal penal. Instrucciones generales $N^{\circ}$ I a 25, septiembre-noviembre 2000 (Santiago, Editorial Jurídica de Chile, 2000).

Ministerio Público, Fiscalía Nacional, Unidad Especializada de Tráfico Ilícito de Drogas y Estupefacientes, Manual sobre interceptaciones telefónicas,.

NúÑez VÁsQuez, Juan Cristóbal, Tratado del proceso penal y del juicio oral (Santiago, Editorial Jurídica de Chile, 2002), II.

Ortiz Schindler, Enrique - Medina Ramírez, Marco Antonio, Manual del nuevo proceso penal (Santiago, Librotecnia, 2005).

Pastén Pérez, Dagoberto, Régimen jurídico de las medidas de interceptación de las comunicaciones telefónicas previstas en el Código Procesal Penal (Tesis, Universidad de Valparaíso, Chile, Escuela de Derecho).

Pfeffer Urquiaga, Emilio, Código procesal penal. Anotado y concordado (2a edición, Santiago, Editorial Jurídica de Chile, 2006).

Piedrabuena Richard, Guillermo, Exposición del fiscal nacional en la Universidad de Concepción sobre "Los ajustes a la Reforma Procesal Penal", 28 de septiembre de 2001, en Revista Jurídica del Ministerio Público, 5 (septiembre 2001).

Piedrabuena Richard, Guillermo, Exposición del fiscal nacional en la Universidad Mayor de Temuco sobre "Estado actual de la Reforma Procesal Penal", 20 de diciembre del 2001, en Revista Jurídica del Ministerio Público, 8 (diciembre 2001).

Piedrabuena Richard, Guillermo, Informe y comentario acerca de las modificaciones al Código Procesal Penal introducidas por la ley 19.789, contenidos en el Oficio Circular $N^{\circ} 053$ de fecha 29 de enero de 2002, en Revista Jurídica del Ministerio Público, 9 (marzo 2002).

PisAni, Mario, Manuale di procedura penale ( $8^{a}$ edición, Bologna, Monduzzi, 2008), capítulo $17^{\circ}$ [de Oreste Diminioni].

Tavolari Oliveros, Raúl, Instituciones del nuevo proceso penal. Cuestiones y casos (Santiago, Editorial Jurídica de Chile, 2005).

Tonini, Paolo, Manuale di procedura penal (11 a edición, Milano, Giuffrè, 2010).

Weezel van, Alex - Darricades, Tomás, Interceptaciones telefónicas. Oportunidad para avanzar, en Revista del Abogado del Colegio de Abogados de Chile, 52 (julio de 2011).

Zapata García, María Francisca, La prueba ilícita (Santiago, LexisNexis, 2004).

Zavidich Diomedi, Carolina, Restricción a las comunicaciones telefónicas en la ley de drogas chilena, en Revista Jurídica del Ministerio Público, 44 (septiembre 2010). 